\title{
Failure assessment for drinking water distribution system in the case of Bahir Dar institute of technology, Ethiopia
}

\author{
Roman Abebe Mesalie ${ }^{1} \cdot$ Dagnachew $_{\text {Aklog }}^{2,3} \cdot$ Mekash Shiferaw Kifelew $^{1}$ (I)
}

Received: 28 February 2021 / Accepted: 24 June 2021 / Published online: 15 July 2021

(c) The Author(s) 2021

\begin{abstract}
In this paper, the issue of failure assessment in the drinking water distribution system was presented. This specific study was conducted on the water distribution system on the campus of Bahir Dar Institute of Technology. The current problem in Bahir Dar institute of technology is that the water infrastructure is aging and has not been spending adequate to repair, replace, or rehabilitate drinking water distribution systems. This develops higher stresses on the water distribution network causing pipes to crack, or rupture permanently while in service. Due to this problem, the whole water supply components in the distribution network led to increased water loss and quality reduction. The general objective of this study is to assess the risk of the water distribution system in the Bahir Dar Institute of technology water supply distribution system. In this study, a structural risk assessment was developed by using ARC GIS 10.5 and Water Cad V8i to get prioritize maps of the water distribution system and hydraulic analysis of the drinking water distribution system of the institute. In developing this assessment, the score was established based on the preset criteria to evaluate customer point risk and structural point risks such as water quality, water availability, pressure head adequacy, the flow rate of water, pipe, storage facility, and pump. Based on the result obtained from an equal weight approach, the score of the drinking water distribution system risk index is a medium level (2.56) with a low level of structural risk (2.5) and a medium level of consumer point risk (2.62). The results evaluated by the AHP method, structural risk has had the highest weight score (76\%) which means it needs more priority than consumption point risk (24\%), and the result of drinking water distribution system risk index laid at the medium level (2.7), it indicates the institution drinking water distribution system put at the satisfactory condition with the sum up the effect of medium structural risk index (2.65) and medium consumption point risk (2.82). Based on the findings and conclusions of the study, the components of the campus water supply distribution system, particularly parts of the pipe and the majority of the pump, should be replaced before they become obsolete, and suitable preventive measures should be taken.
\end{abstract}

Keywords AHP method $\cdot$ Equal-weight approach $\cdot$ Failure assessment $\cdot$ Failure risk index $\cdot$ Water quality index

\section{Introduction}

Water distribution networks are the most vital and expensive infrastructural assets Kabir et al. (2015). The provision of a water supply scheme shall ensure a constant and reliable water supply to the community for which it has been

Mekash Shiferaw Kifelew

mekahydro@gmail.com

1 Faculty of Technology, Debre Tabor University, Debre Tabor, Ethiopia

2 School of Civil and Water Resources Engineering, Bahir Dar Institute of Technology, Bahir Dar, Ethiopia

3 Blue Nile Water Institute (BNWI), Bahir Dar, Ethiopia designed. The water supply system has to provide consumers with the required amount of water having proper quality, required pressure, and flow according to the valid standards acceptable by consumers, and at a time convenient for them K. Pietrucha \& Tchórzewska (2017).

The deterioration of urban water distribution systems presents a major challenge to water utilities throughout the world. This deterioration can lead to break and leak which may result in a reduction in the water carrying capacity and lead to substantial repair cost and can also pose potential dangers and contaminating the water in the distribution system Yamijala et al. $(2007,2008)$. Therefore, planning, constructing, and managing an appropriate water supply system can provide adequate quantity and good quality of water. 
K. Pietrucha (2015) stated that system shall not only help in supplying safe wholesome water to the people for drinking, cooking, bathing, washing, etc. to keep the disease away and thereby promoting better health but would also help in supplying water for fountains, gardens, etc., and thus helping in maintaining better sanitation of surroundings. Besides promoting overall hygiene and public health, it shall further help for firefighting and industrialization. An examination of the transmission process of drinking water reveals the great importance of pipelines. Water pipelines delivering water today may encounter serious problems. A properly maintained distribution system can potentially decrease negative impacts on our environment by avoiding substantial water loss through preventative maintenance against leaks, cracks, and pipe breaks during normal operations. The pipe elements that already provide the service in the water distribution system are damaged due to various factors. Leakage and water loss occur as a result of these failures. Therefore, it is quite important to evaluate the technical performance of the water supply distribution system providing service in older water distribution systems and to replace that having the potential damage risk Jan Carlo Devera (2013).

Failure assessment is abroad filed to the management of the water distribution system Leonard et al. (2004). It applies to evaluate the performance of existing water distribution systems (WDS), which began in the 1970s. The assessment focused on the future water supply operation safety and management of urban water distribution systems Sun and $\mathrm{Yu}$ (2013). Agrawal and Sinha (2015) define failure assessment as a process to identify possible exposure and analyze what could happen if the hazard occurs. Failure assessment is contributed to specific projects, methods, procedures, and tools of system control, thus preventing failure from occurring.

Lindhe A. (2010) describes failure risk assessment are initiated by decision problems and the aim is to provide relevant and accurate information to support the decision. The character of the system control should distinguish the importance of determining the consequences of an undesirable event, the explanation of the cause of the event, which aims to illustrate the future course of the water system functioning. Considering failure occurrence in the water supply system it can be concluded that no general classification of failure allows for a clear assessment of causes and sources of failure and possible human errors. However, we can distinguish the causes of failures Cubillo and Pérez (2014); Pietrucha-Urbanik (2015)).

According to the 2017 joint monitoring program (JMP) Ethiopian report, the use of drinking water source facility type estimates improved all pipe urban water distribution system is estimated at $88.4 \%$ and non-piped is $9.4 \% \mathrm{WHO} / \mathrm{UNICEF}$ (2017). Based on the reports failure of the piped system means breaking continuity and its operation or becoming partially or totally out of operation which can result in disruption of water supply to the consumers with the proper quality and appropriate pressure Pietrucha-Urbanik (2015). Deterioration of the water distribution system generally implies the impairment of the value or usefulness of the system or it reflects the failing from higher to lower level in quality, character, or vitality of the system. Deterioration of water mains causes a reduction in structural capacity and hydraulic capacity of the water distribution system Mohamed et al. (2014).

Zhou (2018) describes the deterioration of the water distribution system cause many adverse effects to service providers and consumers by an increase in the number of breakages, leakage, roughness growing, and water quality reduction. For the user, this reduces the quality of service, and service provider results increase in the cost of operation and maintenance. The deterioration of water supply components can be classified into two categories. The first is the structural deterioration which diminished the distribution system's structural resiliency and its ability to withstand the various type of stress. The second deterioration inner surface of the distribution system diminished hydraulic capacity and water quality (Kleiner \& Rajani 2001a, b). In the face of some differences, the presentation objectives for risk of failure of water mains can broadly be categorized as the structural risk of failure (pump, pipe, and storage facility) and customer-based risk (Water availablity, water quality, pressure head adequacy, and flow rate of water).

The objective of this study includes (i) the development of a practical failure assessment method that was both easy to understand and easy to use small data availability, (ii) assessment of the risk linked to the structure by selecting main and sub-main factors, and (iii) assessment of the risk associated with customer point based on the selected factors to evaluate the risk of water main failure considering the structural risk of failure and, costumer-based risk and impact factors. (iv) This paper further explores both knowledge and data-based pairwise comparison method to evaluate the water main failure risk index that can be used to rank or prioritize the water main in a network system for Bahir Dar institute of technology's water supply distribution system. Such decision support systems will aid the institute water utility manager to better address the structural failure of water mains and consumer point risk, proactively, while meeting financial constraints, level of service interruption, and urgent regulatory requirements. Finally, the developed methodology helps a similar institution and other urban cities to evaluate their drinking water distribution system.

\section{Methodology and material used}

\section{Description of the study area}

The institute is located in the northwest of Bahir Dar town at $11034^{\prime} 28^{\prime \prime} \mathrm{N}$ latitude and $37021^{\prime} 44^{\prime \prime} \mathrm{E}$ longitudes and it 
has an elevation of 1800.145 m.a.s.l. The total pipe length of the BIT water distribution system is $2473 \mathrm{~m}$ and composed of Galvanized Iron (GI) pipes (98\%) and the remaining 2\% were polyvinyl chloride (PVC) pipes supplied through 5 reservoirs, 3 of which are concrete made and 2 are pioneer type of reservoirs. The current total population of the BiT campus is estimated to be 8,165 .

\section{Existing water supply condition}

According to the field visit, water is distributed to each block in Bahir Dar university institute of technology by gravity and pumping from the two main reservoirs that come from the Bahir Dar city municipality water mains. The distribution lines are laid out in BiT following the existing roadways and the available open space between blocks. Source one for pressure was illustrated in AWWA (1999). Stage of procedure for structural failure risk assessment;

1. To determine the future service life of the components that take to consider the installation year and /or construction year, a material used for construction as well as production. e.g., pipe (age, material, pressure, diameter, length).

2. The second stage involves quantifying the consequence associated with the failure of individual components (tank, pipe, and pump). The consequence is comprised of the impacts which include the cost of materials for replacement. The consequence of a component is assigned a score based on their degree of impact and is totaled to reflect an individual component degree of an impact if it were to fail.

3. A third of the analysis involves combining the result from the first two-stage and quantifying each component's failure the risk of failure then means highlighting the most critical components within the distribution system by categorizing them based on their risk score.

Risk of failure score $(R F S)=$ probability of failure score $(P F S) *$ impact score $(I S)$

is located on the western side of the BiT, and source two is located on the south side of the campus. Input water to the institute comes from two different water sources. The zone one distribution system, which is located on the major road towards the Gondar side of the Abay Bridge, receives water from the Chara Chara and Enfranz wells (Fig. 1).

\section{Risk of failure for water mains}

Assessing the risk associated with the structural element as mentioned previously, the structural component of the water supply system of BiT is composed of reservoirs, pumps, water meters, pipes, and fittings (valves, bends, joints, etc.). The risk assessment of every component is a little bit difficult, cost-intensive, and recorded data needed. The major components used for water supply are selected to analyze the risk of failure due to the above mention selection reasons as well as an area with a recorded number of risks this would allow for the identification of components that should be urgently replaced and maintain. For assessing the risk level of the pipe first all it should be analyzed the distribution network by using water cad v8i software. To calibrate the model, some junction accessible and available for pressure measurement is needed. But in the case of BiT measured pressure is on the faucet which is nearest to the junction. Due to the junction has been lined with asphalt and concrete so, it cannot easily measure the pressure without excavation of the road. Limited obtainability of fund for excavation and relined the road and in addition to this the size of pressure gage availability. The acceptable level of calibration criteria
Risk of failure index $=\sum$ weight of factors $*$ RFS

4. Finally, each category is assigned a color to help create an easy-to-understand visual of the result within arc GIS 10.1 for better visualization.

\section{Assessing the risk linked to customer}

\section{Assessing the water quality}

The water quality (WQ) status of any water body is highly uncertain and subjective A. Kumar et al. (2017); A. Kumar et al. (2021). Several processes and factors are affecting water quality during transmission and distribution (Fig. 2). The deterioration of drinking water distribution infrastructure is among the main causes of the loss of water quality and quantity of drinking water at the consumer's tap. However, the major portion of the distribution system is underground, its deterioration does not the same visual urgency as other visible infrastructure. Since deterioration of the distribution infrastructure adversely affect the water quality. In another way, the deterioration of water mainly results in a reduction in water quality, reduction in quality of service, and loss of water. The water quality index (WQI) is the most widely used indicator for categorizing and providing a general view of drinking water standards by converting drinking water information obtained from numerous criteria into a single value/rating B.V. Deepika, et al. (2020). Different statistical approaches can be used for transformation. Various parameters have different

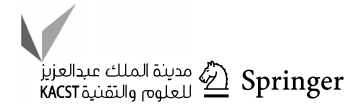




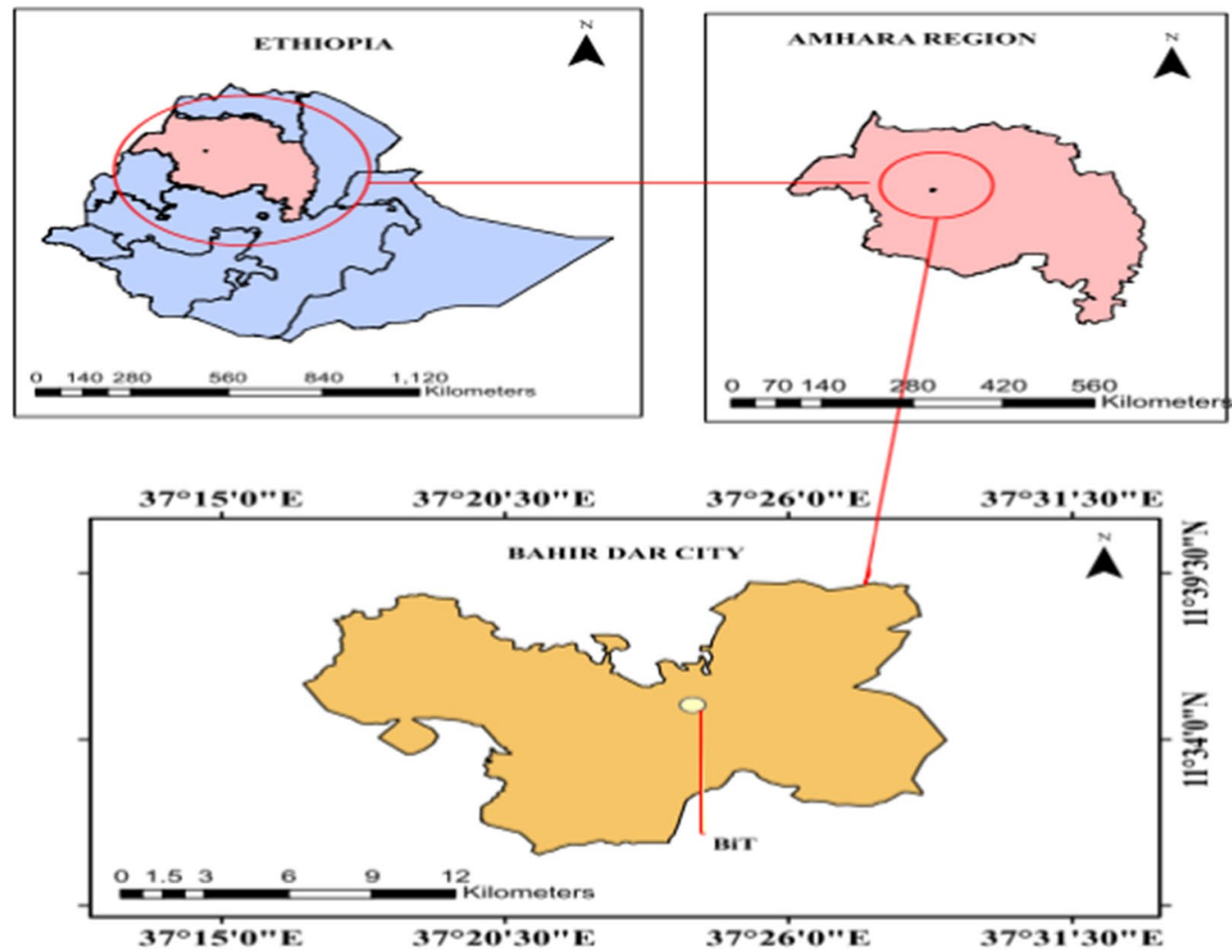

$37^{\circ} 23^{\prime} 40^{\prime \prime} \mathrm{E}$

$37^{\circ} 23^{\prime} 50^{\prime \prime} \mathrm{E}$

$37^{\circ} 24^{\prime} 0^{\prime \prime} \mathrm{E}$

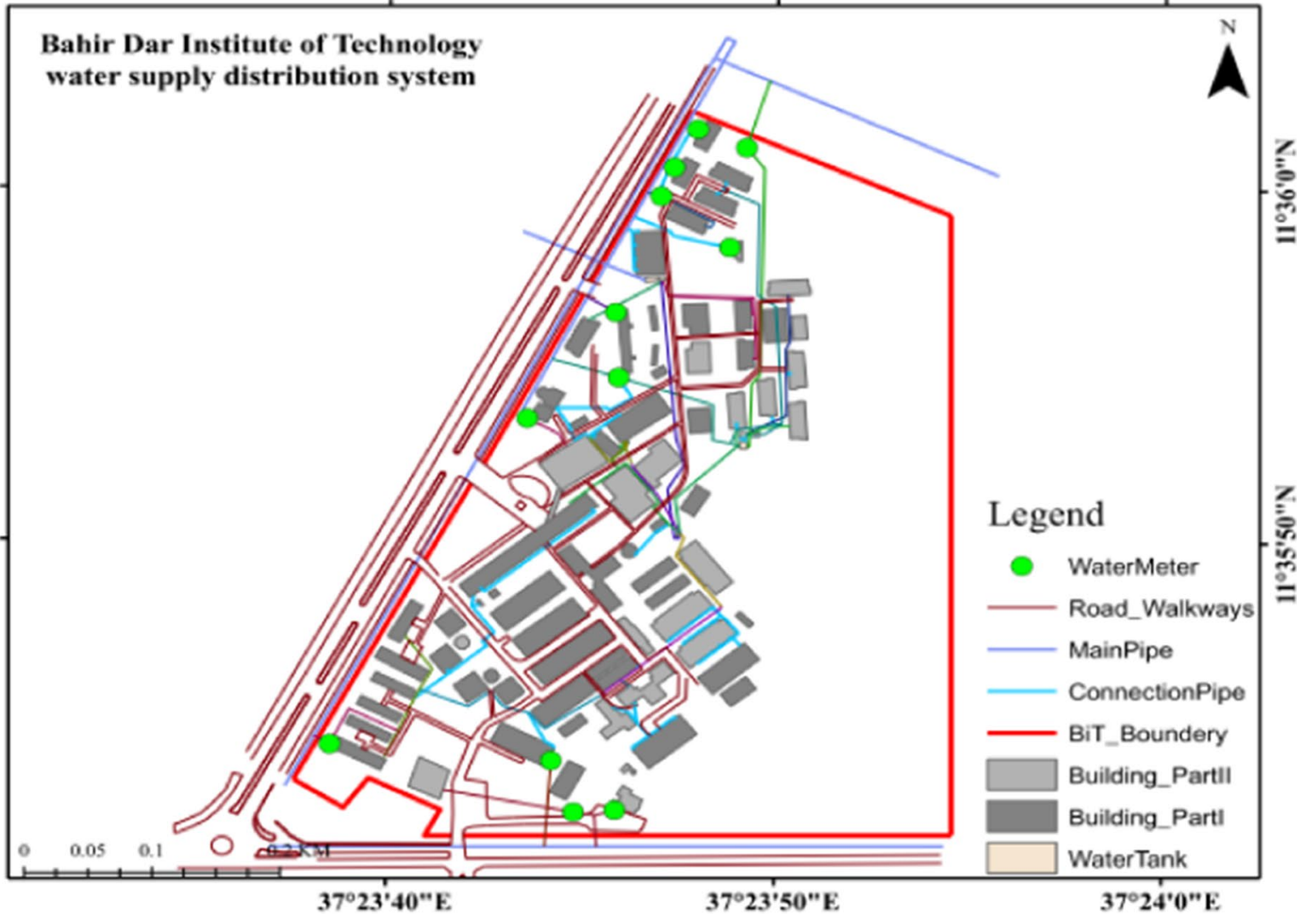

Fig. 1 Location map of the study area 
Fig. 2 Detail research method diagram risk assessment for water quality

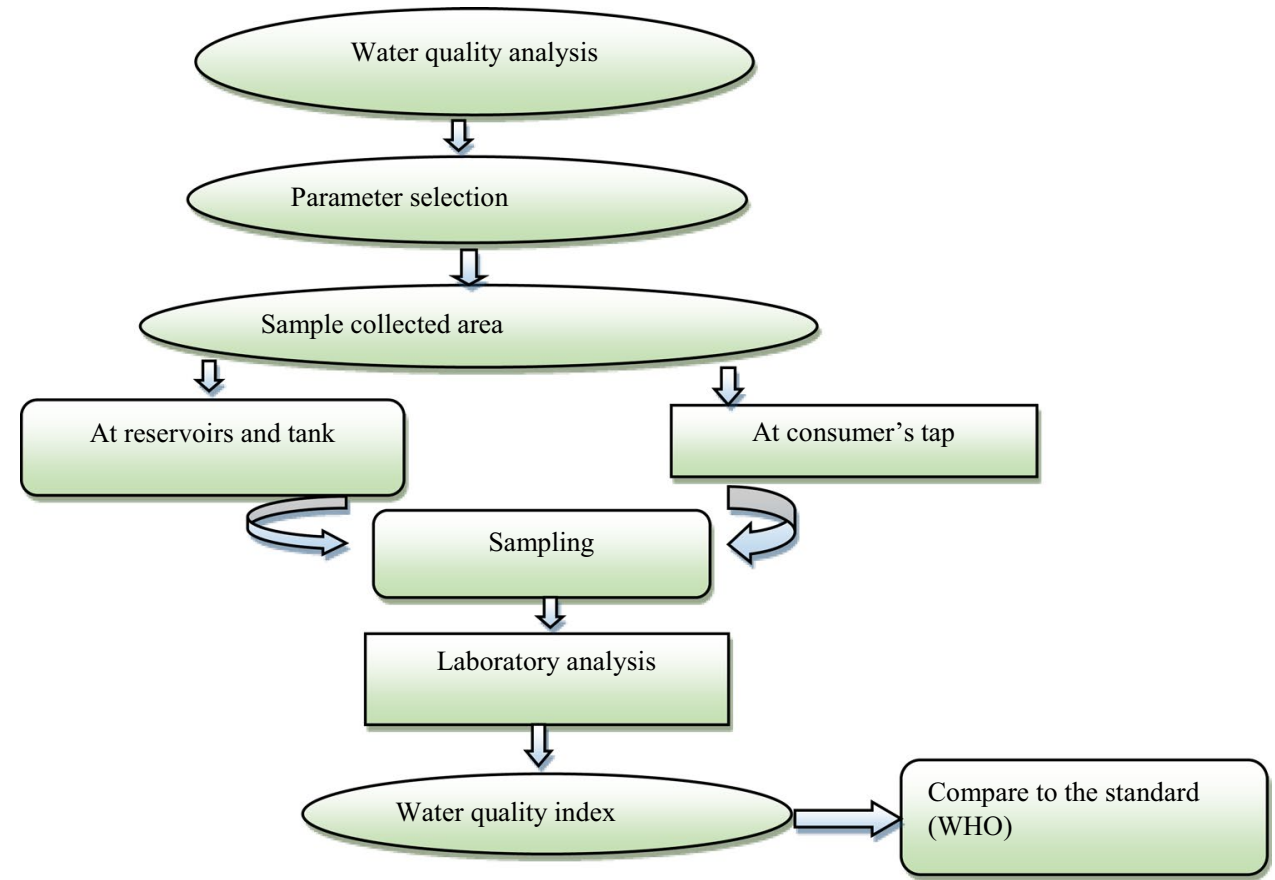

units as well as ranges. By transformation process, all the parameters are transformed into a common scale and sub-indices generation four different methods are used in the world are national sanitation foundation water quality index (NSFWQI), Canadian council of ministries of the environment water quality index (CCMEWQI), origin water quality index (OWQI) and weightage arithmetic water quality index method (WAWQI). NSFWQI Mishra, S. and Kumar, A., (2021) and WAWQI Chandra et al. (2014) are the most commonly used WQI for the classification of WQ status. In this study, the estimation of water quality is by using the weightage arithmetic water quality index method. Weightage is assigned to each parameter according to their importance and potential impacts on the water quality. In this study, the reason to select the weighted arithmetic index method Water Quality Index (WQI) method is it has an advantage over other methods multiple water quality parameters are incorporated into the mathematical equation that rates the level of suitability of water quality to the human consumption and/or also describe the level of contamination. It is a well-accepted and universally applicable method for evaluating the water quality index (Table 5). Procedures for calculation of water quality index by using WAWQI methods are;

1. Collect the data for various water quality parameters

2. Calculate the probability constant " $K$ " value using the formula

$$
k=\frac{1}{\left(1 / \sum \sum_{i=1}^{n} s n\right)}
$$

3. Calculate quality rating for $n^{\text {th }}$ parameter $\left(q_{n}\right)$ where there is an " $n$ " parameter this is calculating using the formula

$$
q n=\left(\frac{(v n-v i o)}{s n-v i o)}\right) * 100
$$

$\mathrm{v}_{\mathrm{n}}=$ estimated value of the $\mathrm{n}^{\text {th }}$ parameter of the given sampling station, $\mathrm{v}_{\text {io }}$ ideal value of the $\mathrm{n}^{\text {th }}$ parameter, $\mathrm{s}_{\mathrm{n}}=$ standard permissible value of the $\mathrm{n}^{\text {th }}$ parameter.

4. Calculate unit weight for the $\mathrm{n}^{\text {th }}$ parameters

$$
w_{n}=\left(\frac{k}{s n}\right)
$$

5. Calculate the water quality parameter (WQI) using this formula;

$$
W Q I=\left(\frac{w n * q n}{\sum w n}\right)
$$

\section{Parameter selection}

The parameter should represent overall water quality status and reflect each impairment category for water distribution systems including the physical characteristics and human health aspect WHO $(2014,2018)$. Besides, parameters that are often monitored and have known key effects on drinking water quality should also be selected. All parameters that were covered in this study are included; physical (temperature, conductivity, turbidity, and TDS), 
Table 1 Selected factor for failure of distribution system assessment

\begin{tabular}{|c|c|c|c|}
\hline \multirow[t]{2}{*}{ Components } & \multicolumn{3}{|l|}{ Selected factor } \\
\hline & Physical & Economic & Operational \\
\hline Pipe & $\begin{array}{l}\text { Material type } \\
\text { and Age } \\
\text { Length } \\
\text { Diameter }\end{array}$ & Cost & Pressure \\
\hline Pump & $\begin{array}{l}\text { Age and Material } \\
\text { /type }\end{array}$ & Cost & $\begin{array}{l}\text { Working hour/ } \\
\text { day and On/ } \\
\text { Off per day }\end{array}$ \\
\hline Storage facilities & $\begin{array}{l}\text { Age and The } \\
\text { material used for } \\
\text { construction }\end{array}$ & Cost & \\
\hline
\end{tabular}

chemical ( $\mathrm{pH}$ as well as the concentration of nitrate, residual chlorine, iron, and total hardness), and biological (total coliform).

\section{Sampling and sample size}

The sample point was selected such that the sample is taken representative of the different sources from which water is obtained by the institution to enter the system. The sample collected area should be represented the physical, chemical, and biological property of the area because of guaranteeing the validity of analytical findings. In the case of BiT, it is difficult to examine the water, quality based on population. So, to assure the collected sample soundness, the sample collected area is sated based on the number of dormitories and residence houses taken as a household (Fig. 3). The number of sample sizes was calculated by using the following formula; (Mohamed et al. 2014).

$n=\frac{\left\{\frac{(z x)^{2}}{2} * p *(1-p)\right\}}{d^{2}}$

Table 2 The Factor Contributing to Pipe Failure and their evaluations

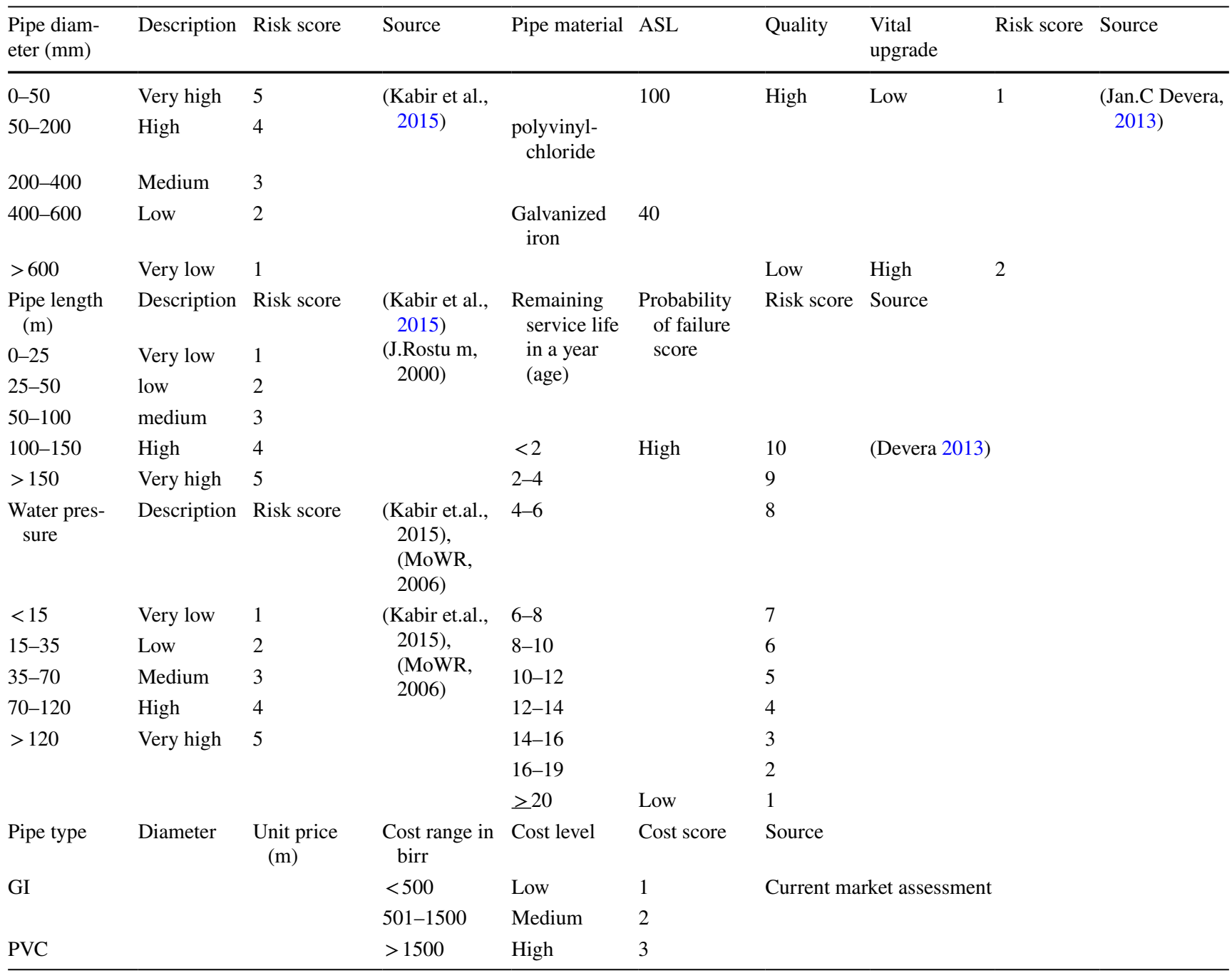


Where: $\frac{z x}{2}=1.645, \mathrm{p}$ is the ratio of the sum of dorm number, $\mathrm{d}$ is accepted error and staff residence number of households.

in BiT (514) to the total number of houses in the BiT (806), $\mathrm{d}$ is the accepted error of $10 \%$. By substitute the above equation, the number of sample sizes is 8 . from this total of 8 sampling points were used for water quality assessment, and additionally, the water sample from the nearby reservoir and tank five samples were taken. The sample size of water flow rate and pressure head at the tap was determined by using the same water quality sample size by excluding the nearby reservoirs and tank which is additionally considered in water quality analysis sample size. The questionnaires were designed for prioritizing drinking water risk assessment criteria was completed by a total number of 20 experts and professionals from Bahir Dar city water supply and sanitation service office, Amhara design and supervision work enterprise, and Amhara national regional state water, irrigation, and energy development bureau, and Bahir Dar university institute of technology water supply and sanitary engineering lectures. The importance of the questioner after gathering and used for the multicriteria decision-making process.

\section{Sampling frequency and sampling techniques}

Selecting the water sample is one of the most important tasks. Water samples were taken from different places to decrease the error the sample is taken to analyze every wet and dry season twice per one season from April to August of the year 2019 G.C. Samples were collected at the reservoir, tank, and taps from the distribution system. All measurements were carried out in duplicate, and the results were expressed as averages to compensate for the technical error during the water quality analysis. The reason for used a high number of frequencies for sampling is to get representative water quality for the study area. The sampling technique used for this study is the grab sample.

\section{Assessing the flow rate and pressure head adequacy}

There is sufficient pressure at the point of supply to provide adequate flow to the consumers Kabir et al. (2015). It was assumed that the flow rate through a pipe was representative of the number of users drawing from that pipe. Water pressure may vary for place-to-place water due to old infrastructure issues with the system or being located a long distance from the main water line. The pressure head adequacy and flow rate of water were directly measured on the customer's tap and compare with national and international standards to evaluate customer point risk.

\section{Data Collection}

All the necessary data required for this study was obtained from both primary and secondary sources. Primary data was collected by field survey, water quality analysis, tap water flow, and pressure observation of the study area. Global positioning system (GPS) was used to collect point location for all the existing water supply system networking for assessing in the institution, Digital camera and were conducted to capture primary data. Primarily collected data on a field survey is pipe material, Pipe diameter, Pump location, and working hour, tank, and reservoir dimensions. Secondary data reviewed to understand the existing water supply system management practice at the institutional level and obtained from a cadastral map in the form of AutoCAD, old water supply network, the number of populations from human resource and registrar office, written document, and internet sources are used to collect the secondary data (Fig. 4).

\section{Data analysis}

\section{The influential factor for water distribution components failure}

Each system element is linked to an individual failure probability which depends on the type, inherent characteristic, condition, and status of each one Cubillo and Pérez (2014) (Fig. 4). The importance of different factors that are used to evaluate the risk of major water supply distribution system components failure is selected by different literature reviews by reviewing the characteristics of those factors and the effect of the characteristics on the risk of components failure (Table 1). The selection of different factors quite different researchers and water supply distribution systems. Because some influence factor values are difficult or impossible to obtain completely because of a lack of available data recorded in the institute. Spatial and temporal variability and randomness also result in a complicated impact. Therefore, some significant and available factors are usually selected in water supply components risk of failure assessment in the institution. Among numerous influence factors, the principles of choosing a part of the factors to carry on the probability of the component of failure assessment are Zhou (2018); Lee (2012); J. Devera (2013); Cortez (2015); Selvakumar and Natarajan (2015). 


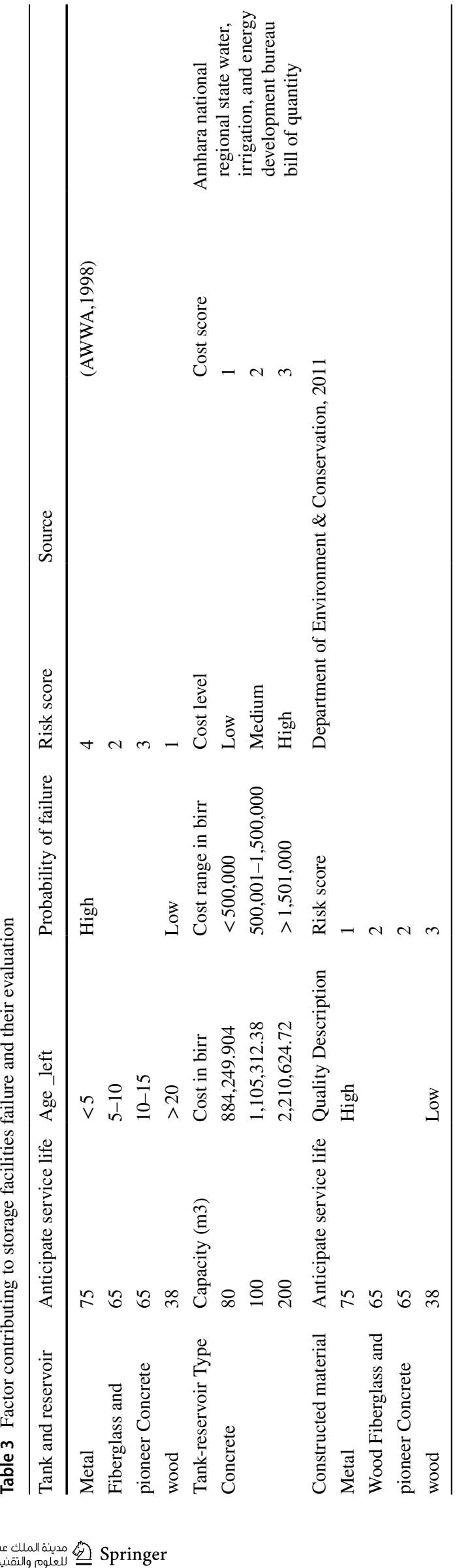

\section{The factor contributing to pipe failure}

The pipe material of the water main is a very important parameter of the performance of the pipe. The resistivity of different loads, corrosion resistance, strength against pressure, and life expectancy Dong Chen et al. (2013). Some materials are performing better than others depending on the required size and length of the water main. The most common type of pipe in the Bahirdar university institute of technology water supply distribution system covers $98 \%$ of GI pipe in a whole system and the reaming $2 \%$ is polyvinyl chloride (PVC). The diameter of the pipe is one factor that contributes to water main deterioration. Al-barqawi and Zayed (2006); A. J. Kettler and C. Goulter (1985) found a strong linear negative correlation between pipe diameter and break rate. The break rate of the water main decreases as the diameter of the pipe is increased. Usually, large diameters are will used for transmission main. However, a small one is a will used for distribution main as well as connection pipe. Due to this, the pipe failures for the distribution main are higher than those for transmission main failure for many reasons pressure stability, operation, and maintenance process, and rehabilitation work for the road for service age. A. J. Kettler and C. Goulter (2010) examines a major reason for the reduction break rate of large size diameter of the pipe is a result of the thicker pipe wall and more reliable joint associated with this large size (Table 2). This greater wall thickness provides an inherently more robust pipe which is not as likely to fail structurally as a result of external loading. According to Kabir et al. (2015) studies, the diameter of the pipe is categorized under different levels and the smaller one has a high-risk score. Pipe length has been considered as one of the basic static parameters for structural integrity and it's measured by the meter Kabir et al. (2015). According to J. Røstum (2000) studies, the probability of failure greater for along pipe than shorter length pipe (Table 2). The pipe failure and break are due to the longer the Pipe length has more affected by traffic load and operational stress like pressure Berardi et al. (2008). Pipe age is measured by a year. There is a strong and positive correlation between pipe age and pipe probability of failure. Hu and Hubble (2007) studies show that the breakage rate would increase with pipe age because of accumulated damage caused by physical, environmental, and operation conditions. A newly installed water pipe usually has a high factor of safety. The Load caring capacity of the buried pipe decreases gradually over time due to deterioration such as that of corrosion in a metal pipe Mudiyanselage et al. (2016). The general trained is that the older pipe age has a higher pipe break rate. The age of the water distribution pipe is an important parameter to assess the risk of the distribution system (Dong Chen et al. (2013). The age of the pipe can be resulting from calculating the 
Table 4 Factor contributing to pump failure and their evaluation

\begin{tabular}{|c|c|c|c|c|c|}
\hline Pump type & Anticipate service life & quality & Upgrade urgency & Risk score & Source \\
\hline Positive displacement & $15-20$ & High & Low & 1 & \multirow[t]{2}{*}{ (Daniel P. Duffy,2018) } \\
\hline Centrifugal & 15 & Low & High & 2 & \\
\hline $\begin{array}{l}\text { Centrifugal Pump age in } \\
\text { a year }\end{array}$ & Probability of failure & Risk score & \multirow{4}{*}{\multicolumn{3}{|c|}{ (inspectapedia.com/water/Well_Pump Life.php) }} \\
\hline $0-5$ & low & 3 & & & \\
\hline $5-10$ & & 4 & & & \\
\hline$>15$ & high & 5 & & & \\
\hline Pump working hour/day & Description & Risk score & \multirow{4}{*}{\multicolumn{3}{|c|}{$\begin{array}{l}\text { (U.S. Department Of Energy Efficiency And Renewable } \\
\text { energy, 2006) }\end{array}$}} \\
\hline $0-8$ & Low risk & 2 & & & \\
\hline $9-16$ & Medium risk & 3 & & & \\
\hline $16-24$ & high risk & 4 & & & \\
\hline $\begin{array}{l}\text { Pump on and off frequency } \\
\text { /day }\end{array}$ & Description & Risk score & \multirow{6}{*}{\multicolumn{3}{|c|}{$\begin{array}{l}\text { (K.Mckee et al. 2005) and (Karassik, Messina, Fraser, \& } \\
\text { Karassik, 2001) }\end{array}$}} \\
\hline$<5$ & Very Low-risk Low & 1 & & & \\
\hline $6-10$ & risk & 2 & & & \\
\hline $11-15$ & Medium risk & 3 & & & \\
\hline $16-20$ & High risk & 4 & & & \\
\hline $20-25$ & Very high risk & 5 & & & \\
\hline Pump horsepower & Pump cost in birr & Pump cost range in birr & Linguistic risk score & Numerical & \multirow{3}{*}{$\begin{array}{l}\text { Current Market Sur- } \\
\text { vey in Bahirdar City }\end{array}$} \\
\hline 20 & 125,000 & $<50,000$ & Low risk & 1 & \\
\hline & & $50,001-100,000$ & Medium risk & 2 & \\
\hline 15 & 80,000 & $>100,001$ & High risk & 3 & \\
\hline
\end{tabular}

number of years since it is the first installation day up to now (Table 2). It's assumed that the pipe was in operation throughout the entire length of time. The age does not take into account the service loss repair and replacement. Many producers of water distribution pipe advertise manufacture recommended service life usually represents a range of a year. The decrease and increase in the service life of the pipe depend on the pipe's material type J. Devera (2013). The following equation illustrates the necessary variables required in calculating the remaining service life in each water main.

$R S L=A S L-$ age of pipe

Where $\mathrm{RSL}=$ remaining service life, level inside the pipeline. Existing theory and some practical methods may consider maximum pressure as a major reason to pipe failure (Table 5). In practice, most pipes across a distribution network will be exposed to varying pressure during daily and seasonal variations of water use as well as due to change in the operation of the system (Rezaei et al. 2015). The hydraulic water cad v8i model is used to predict water distribution network nodal pressure after defining the pipe elevation, flow demand pattern, and basic characteristics of the pipe. A particular pipe average pressure $\mathrm{P}(\mathrm{avg})$ can be calculated by taking the average of two corresponding nodal pressure at the upstream and downstream node (starting and end node) pi and PJ (Kabir et al. 2015);

$A S L=$ anticipated service life, Age of pipe = installation year-presence year

After the remaining service life calculation, its probability of failure has been designated (Table 2). In this study, the methodology used the same manner (J Devera 2013), model. In his model, the probability of failure score is a subjective value that directly represents the probability of failure. He was assigned in this model on the basis that has the remaining service life of a pipe decreases the probability of its failing increase due to inevitable deterioration. The term pressure fluctuation is used to express any alteration in pressure
$P(a v g)=\frac{(p i+p j)}{2}$

The cost of pipe is also defined as the amount of money that may invest to replace the pipe. Since the cost of pipe varies the type of material and size of the pipe (Table 2). This study does not consider the excavation, filling, labor cost, and other appurtenances. The price was obtained from the Amhara national regional state water, irrigation, and 
Table 5 The influential factor for consumer point risk assessment and their evaluations

\begin{tabular}{|c|c|c|c|c|}
\hline Value & Water quality status & Water quality disruption & Water risk score & Source \\
\hline $0-25$ & Excellent & Very Low risk & 1 & (Marcela Niculescu, et al. 2016) \\
\hline $26-50$ & Good & low risk & 2 & \\
\hline $51-75$ & Poor & Medium risk & 3 & \\
\hline $76-100$ & Very poor & Higher risk & 4 & \\
\hline$>100$ & Unsuitable for drinking & Very Higher risk & 5 & \\
\hline Measured flow at the tap $(1 / \mathrm{m})$ & Linguistic risk score & Flow risk score & (Affinity Water, n.d) & \\
\hline $0-5$ & Very High risk & 5 & & \\
\hline $5-10$ & High risk & 4 & & \\
\hline $10-15$ & Medium risk & 3 & & \\
\hline $15-20$ & Very good & 2 & & \\
\hline $20-25$ & Excellent & 1 & & \\
\hline Measured tap pressure $(\mathrm{mH} 2 \mathrm{o})$ & Description & Pressure risk Score & ( Marshet. B, 2019) & \\
\hline $0-4$ & Very low & 5 & & \\
\hline $4-6$ & Low & 4 & & \\
\hline $6-8$ & Good & 3 & & \\
\hline $8-10$ & Very good & 2 & & \\
\hline $10-12$ & Excellent & 1 & & \\
\hline Index (1 /c/day) & Risk score & Water availability risk score & (Gleick H., 2009) & \\
\hline$>50$ & No risk & 1 & & \\
\hline $40-30$ & Medium risk & 3 & & \\
\hline $20-30$ & High risk & 4 & & \\
\hline$<15$ & Very high risk & 5 & & \\
\hline
\end{tabular}

energy development bureau's current market assessment per unit meter of material type. The cost of the pipe was also subjected to the scoring system to express the scoring system homogeneously comparing with the other factors.

\section{The factor contributing to storage facilities failure}

Storage facilities failure is not a new phenomenon one of those major failure reasons is the type of construction material used to construct water storage facilities. The material in the water tank and reservoir can have a significant effect on the life span. Common materials used in the construction of storage facilities are concrete, metal, plastic, pioneer, etc. In this study, the risk assessment is focused on the main distribution system of the institute so, the study used the concrete and pioneer reservoir for evaluation of the risk of storage facilities (Table 3). These storage facilities are also subjected to failure. The design life of the water storage tank can vary based on the material used for construction. Within the same way to pipe, the age of tank and reservoirs are calculated by using the following formula.
Tank or reservoirs age $=$ Construction year - Pr esent year

Age_left $=A S L-($ Tank $/$ Reservoir age $)$

The cost of the tank and reservoir can vary with type, capacity, and location AWWA (1998). The material used for construction is the prime influential factor in the cost. Both tanks have different availability in cost. The cost estimation is based on the Amhara national regional state water, irrigation, and energy development bureau bill of quantity (Table 3).

Table 6 Assessment class for evaluating drinking water distribution system risk Class

\begin{tabular}{|c|l|l|l|}
\hline Class & Numerical Risk index & Linguistic Risk index & Color \\
\hline A & 1 & Very low & \\
\hline B & 2 & Low & \\
\hline C & 3 & Medium & \\
\hline D & 4 & High & \\
\hline E & 5 & Very high & \\
\hline & \multicolumn{2}{|r}{ Source (Kilinç et al. 2018) } \\
\hline
\end{tabular}

Source (Kilinç et al. 2018) 


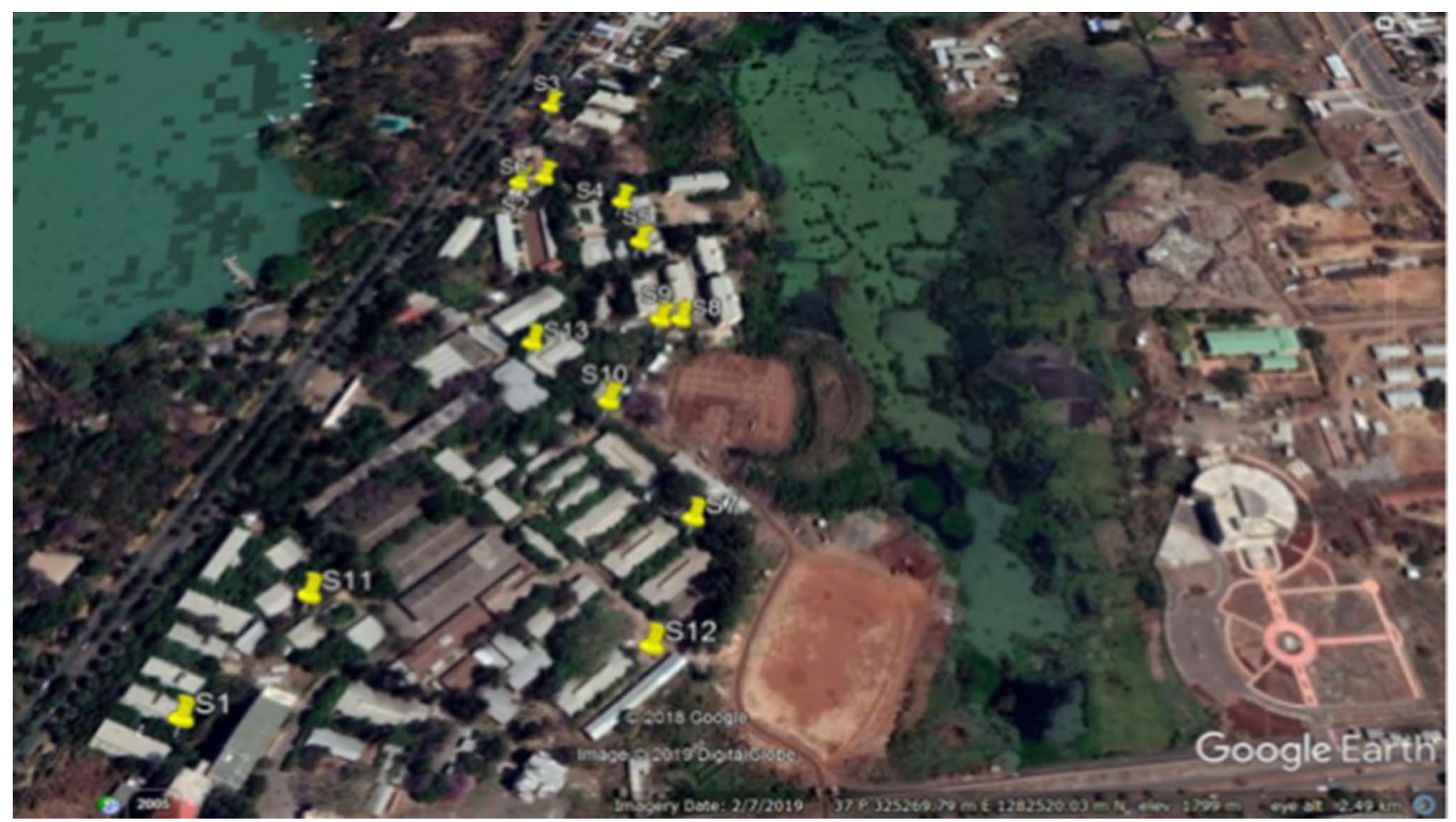

Fig. 3 Water quality sample collected area

\section{The factor contributing to pump failure}

Pumps also play vital roles in the process of distributing water. However, risk sometimes more easily affects pumps than pipes because it is visible and its normal operation depends highly on control, type of pump reliability, and operator's appropriate activity. In risk analysis of pumps, different researchers have to consider all the failure states, i.e., human-caused failure, operational failure, and interdependence failure $\mathrm{Li}$ (2007). The major reason for the failure of the pump is overload, corrosive, and erosive working condition, poor installation, etc. Selvakumar and Natarajan (2015).

In the case of Bahir Dar university institute of technology, all pumps in the two pump houses are centrifugal pump types. In this study area, failure data were collected from the institution water utility service worker and analyzed to identify the weaker pump and frequency of occurring the failure. This study earliest attempts to conduct failure analysis of each pump in the water distribution system to replace and rehabilitation work from the perspective of the service life of the pump, working hours per day, and type of pump itself. The list of pump failure conditions lists below. These pumps work well with thin liquids and offer high flow rates. The type of pump also determined the vulnerability of the pump to fail. The pump type is service life with its manufacture, which its structural strength and its operational strength are expected to remain intact. The pump installation year was used to determine the age of the pump. The age of the pump can be derived from calculating the number of years since its first installation year up to now or the present day. The attribute of this inference to the consequence that is associated with an aging pump is increased failure of a component of the pump (bearing, packing, shaft, and casing). Failure of a component that affects the performance of a pump that causing either reduction in its efficiency or its complete breakdown.

Pump age $=($ installation year of the pump - present year $)$

Then assign the probability of failure score to each pump based on the remaining service life of the pump from the anticipated service life of the pump type (Table 4). In the Water supply system pumps are working for different hours (Table 4). Pump failure can result in equipment overheating due to high operation time without off and catastrophic damage. If the pump is a high working hour the probability of failure of the pump also high (U.S. department of energy efficiency and Renewable Energy 2006). The number of starts per day directly influences the life of components of the pump as well as all pumping systems. Cycling can also cause motor spline or key damage, bearing damage, and motor overheating. All of

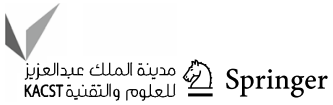




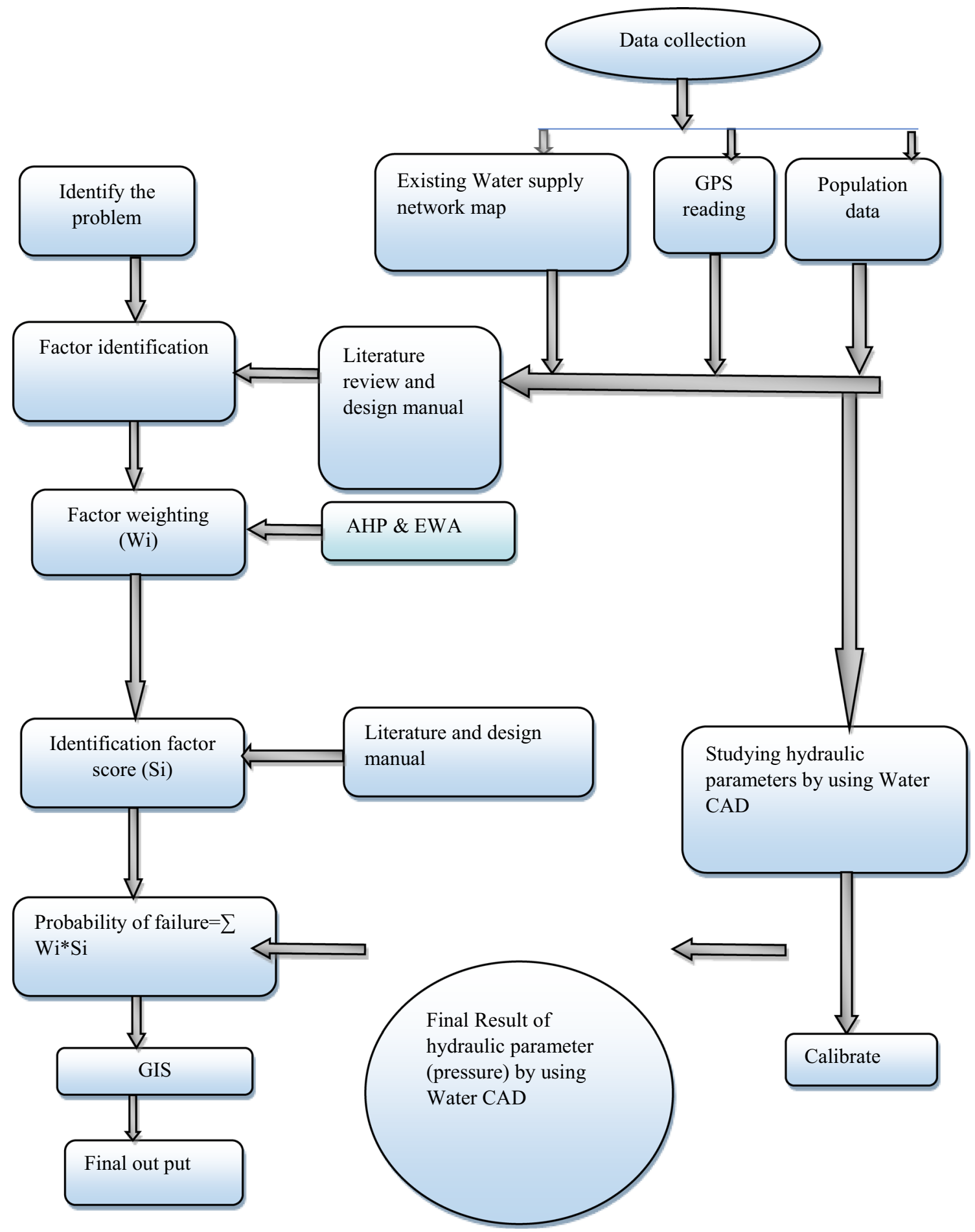

Fig. 4 Schematic diagram for the failure assessment of structural component of the Water distribution system

these conditions reduce the effective life of any pumping system. According to a different study, one of the major three problems attempt to improve the pump operation of the existing pump is inefficient pump scheduling. The frequency of off and on per day increase it will increase the failure of the pump. Based on the literature, maximum and minimum frequencies of start and stop the operation of the pump are in the order of 5 to 25 cycle's in a day K. McKee et al. 2005 and Karassik et al. (2001). Based on this risk 
of failure of the pump seated in the next (Table 4). The cost of the water pump is directly related to the type of pump. In addition to this, the cost of the water pump will be affected by its availability in the market. This evaluation of pump cost does not consider maintenance and power cost it refers to the replacement of the pump after the failure occurs based on the current market survey in Bahirdar city (Table 4).

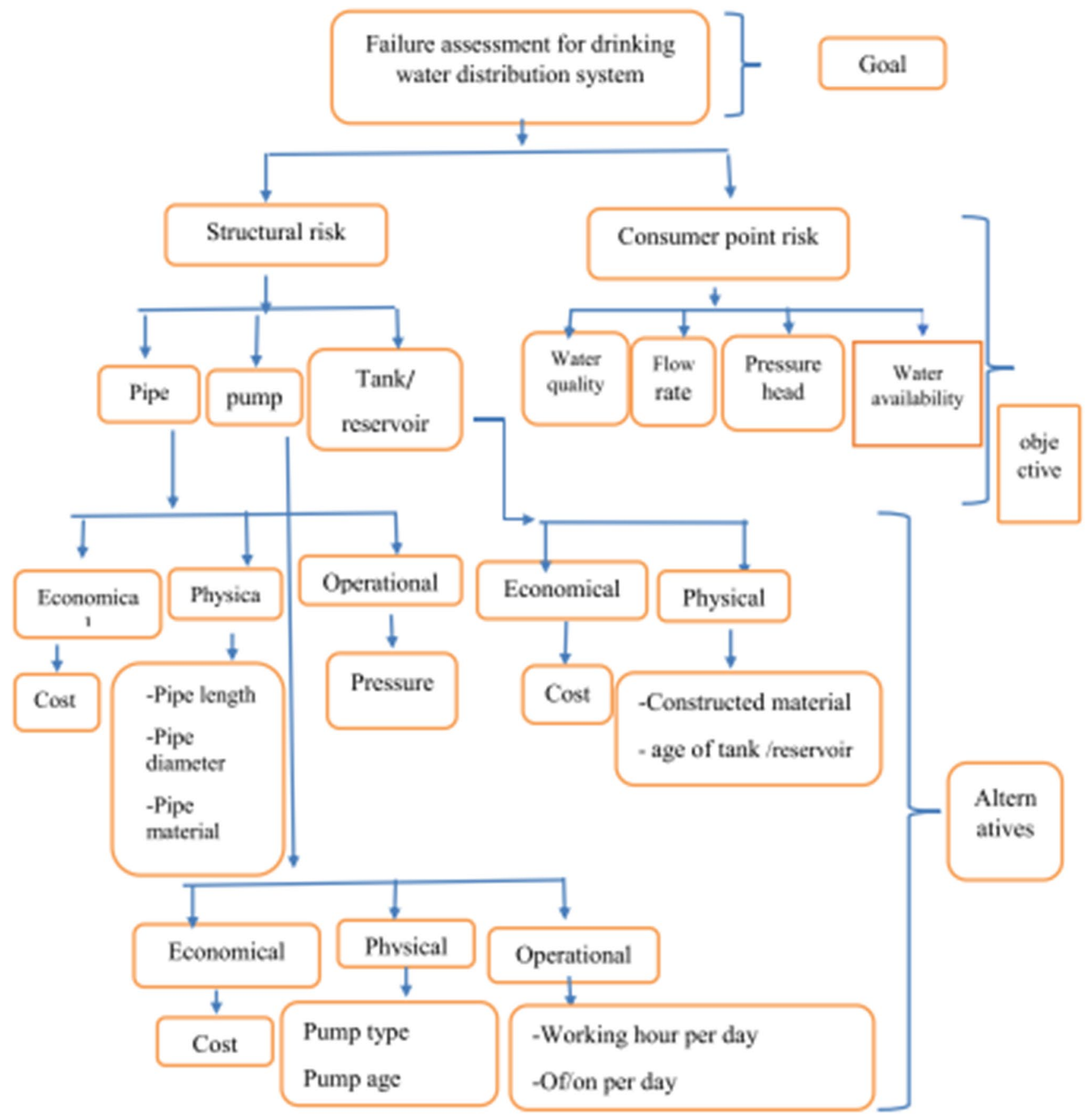

Fig. 5 Flow chart of AHP for risk of failure assessment 


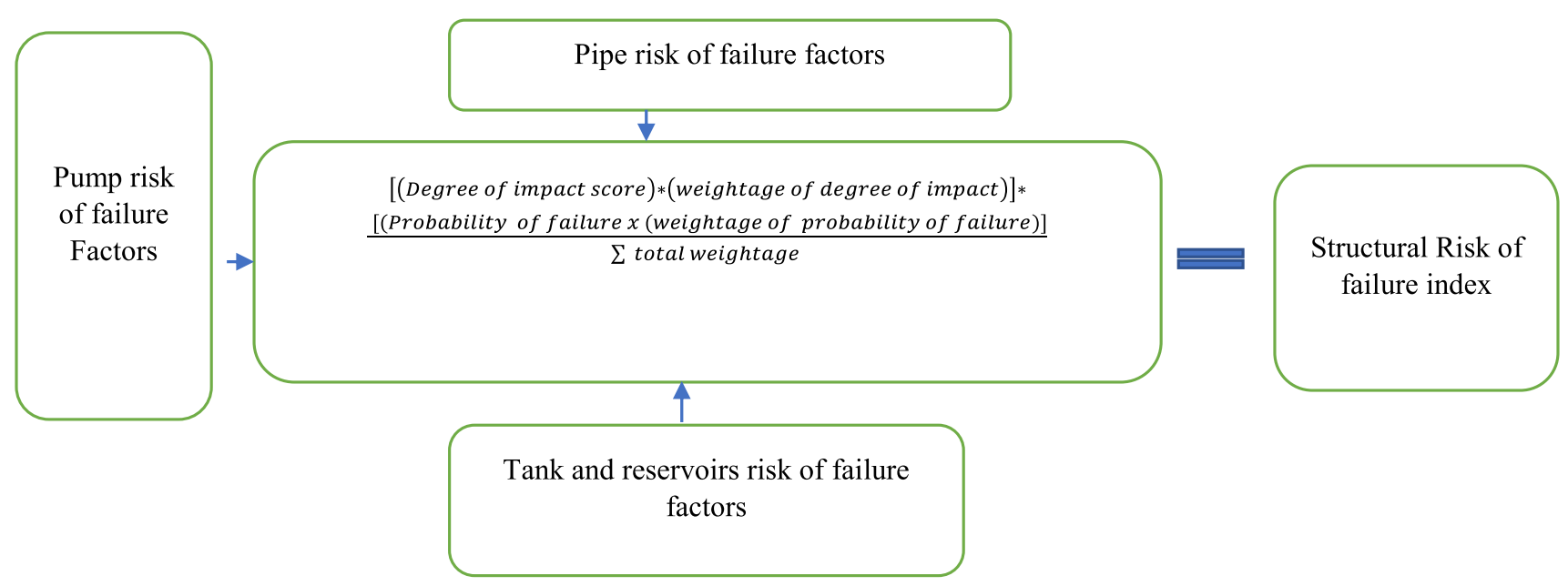

Fig. 6 The risk index formulas

\section{The influential factor for consumer point risk assessment}

\section{Water quality index}

Water quality in the water supply network can be described by specific microbiological, physicochemical, and astatic attributes of water (Kabir et al.2015). The water quality index in the water supply distribution system is commonly used for the detection and evaluation of water quality degradation and it may be defined by the reflection of the composite influence of different quality parameters on the overall quality of water. The water quality index of the study area during the dry and wet seasons is analyzed. The overall water quality parameter during both seasons was analyzed twice to increase the accuracy of the analysis it represents detailed water quality analysis.

\section{Flow of water}

Water flow is the amount of water that passes a valve or tap per minute. The flow of water can measure by using a 1-L jug and a stopwatch. Place the jug under the tap and using the stopwatch to time $6 \mathrm{~s}$ before turning off the tap, then measure the amount of water in the jug in liters. To accurate this test in the cause of BiT, all sample point is measured at the same time due to the reason of using a shared supply pipe (Table 5). If the supply pipe is in poor condition, the amount of water the pipe carries could be restricted and therefore reduce the flow of water to the taps.

\section{Water pressure}

A water pressure reading will tell the exact forecasting of how forceful the water is usually measured in psi. Water pressure is measured at the point where it leaves pipework at the boundary stop tap and flows through the supply pipe. Water pressure does not remain constant and can vary with the water demand is high. the water pressure reading is a great way to monitor the health of the pipe system. A sudden change in water pressure could be a sign of a serious plumbing problem. Low pressure can occur when the pressure in the water main is not enough for water to reach the top of the institution building. Negative or low pressure could also have a significant impact on water quality and public health during this period, there is an opportunity for contaminated water entering drinking water supply systems through leaks, submerged air valves, faulty seals, and other openings (Mudiyanselage et al. 2016). A decrease in water pressure could indicate a serious blockage somewhere in the piping system. Different water service providers have set the preferable value of pressure for water to customers. This preferable value of water pressure at the faucet is between 50 psi. Pressure head adequacy categorized in piped water supply system based on neither too much nor too low to meet the finest water supply-demand to the consumer. Finally based on this preferable value of water pressure, the pressure score set in (Table 5).

\section{Water availability}

The amount of water that the community in need, or use, will depend on its availability (Howard, 2003). In 1989, 

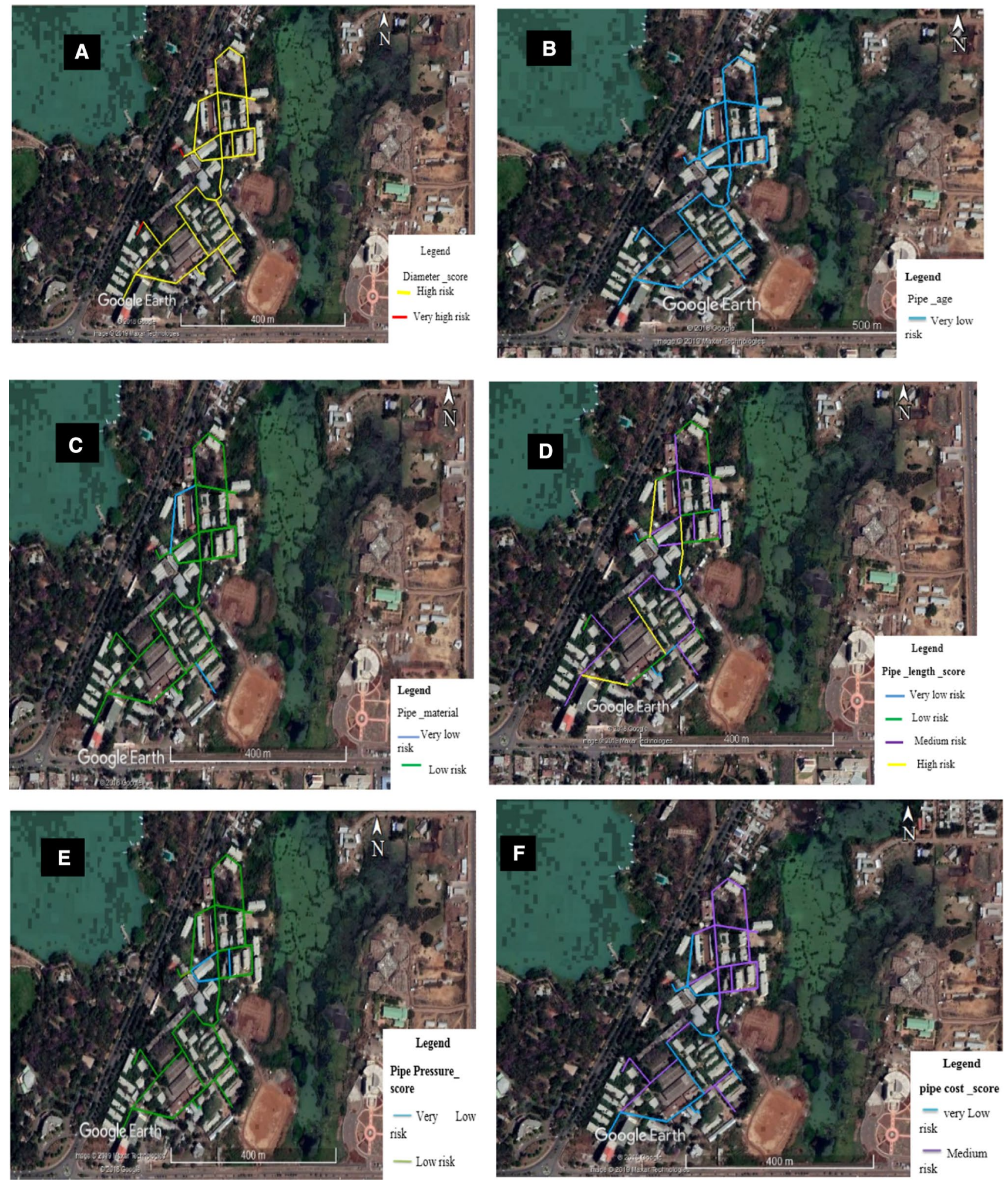

Fig. 7 Prioritize map of pipe risk of failure score (a-f)

Swedish water expert Falkenmark developed one of the most widely used indicators to measure water stress. the indicator is based on the measure of water availability per capita per year within the country or town level. But, in the case of BiT, the amount of water used to satisfy the institution's need is provided by the town water supply service 
so there is no direct production of water in the institution (Table 5). Due to this reason, the safe yield was substituted by the annual consumption of water direct reading from the water bill.

\section{Weights for the risk analysis}

To determine the appropriate weight of the selected factor to evaluate the risk of failure broadly classified as equal weight approach and analytical hierarchy process. Equal weighting is one technique where all alternatives, main criteria's and sub-criteria are equally important for their respective objectives. After selecting the alternatives, subcriteria and criteria have different weights to get a more precise index value when the risk assessment has been applied. AHP process uses the Saaty scale matrix system and Eigenvector principle by using the scale of preference value from 1 (equally important) to 9 (strongly very important). (Table 6)

\section{Estimation of overall numerical risk analysis for BiT}

\section{Aggregated risk rating}

Many researchers have studied a series of risk assessment methodologies, strategies, and methods Sun and Yu (2013) and Ezell et al. (2000). Risk management methods were applied widely in many areas of engineering, but the definition, application, and input data used differ from each other in a different area (Fig. 5).

A risk rating score can vary based on the factor that affects water supply infrastructure and risk at the consumption point. The risk rating scores relative risk scores were the results of the probability of failure and impact score. The total risk score is the product of the two which is also reported 0- 100 scale.

Risk of failure score $=($ probability of failure score $x$ impact score $)$

A risk rating score can vary based on the factor that affects the pipe, tank/reservoir, and pump. The risk rating scores relative risk scores were the results of the probability of failure and impact score (Fig. 6). Finally, after getting the weights of each factor by pairwise comparison, the risk index developed by the next formulas and also reported $1-5$ scale.

Were; WQRIS = Water quality risk score WWQ = weightage of water quality $\mathrm{PS}=$ pressure head score.

$\mathrm{FRS}=$ flow rate score WFRS $=$ weightage of flow rate $\mathrm{WP}=$ weightage of pressure head score.

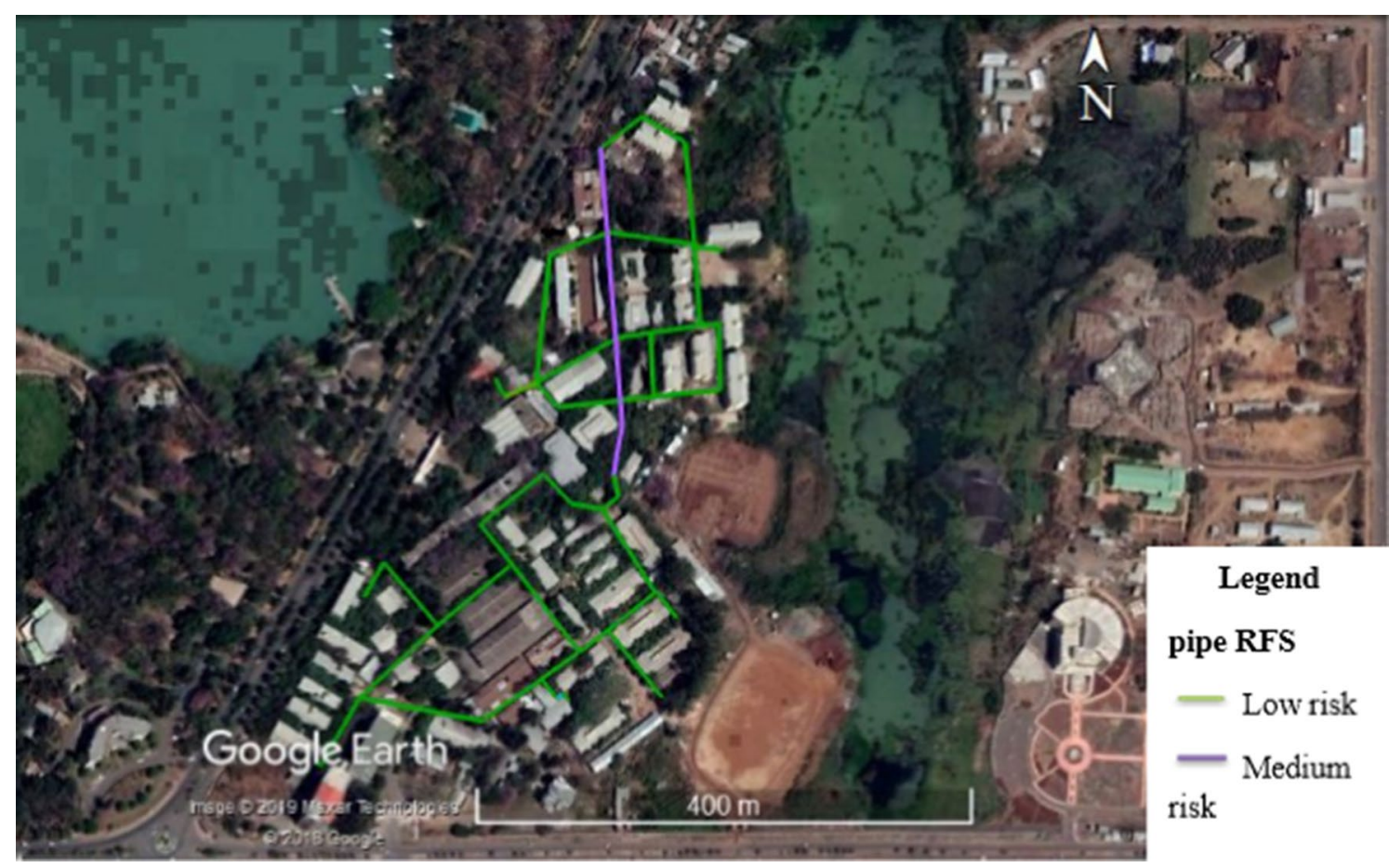

Fig. 8 Cumulative prioritize map of pipe risk of failure score 


\section{Result and discussion}

\section{The failure risk associated with structural components}

This valuation helps to make decisions such as those long and short-term renewal investments. It takes the distribution system component's inherent characteristics and other external factors that affect the system. The factors or the criteria were chosen by determining the risk of individual component failure. Structural deterioration of Bahirdar university institutions of technology water main and their subsequent failure is affected by physical, environmental, and operational factors.
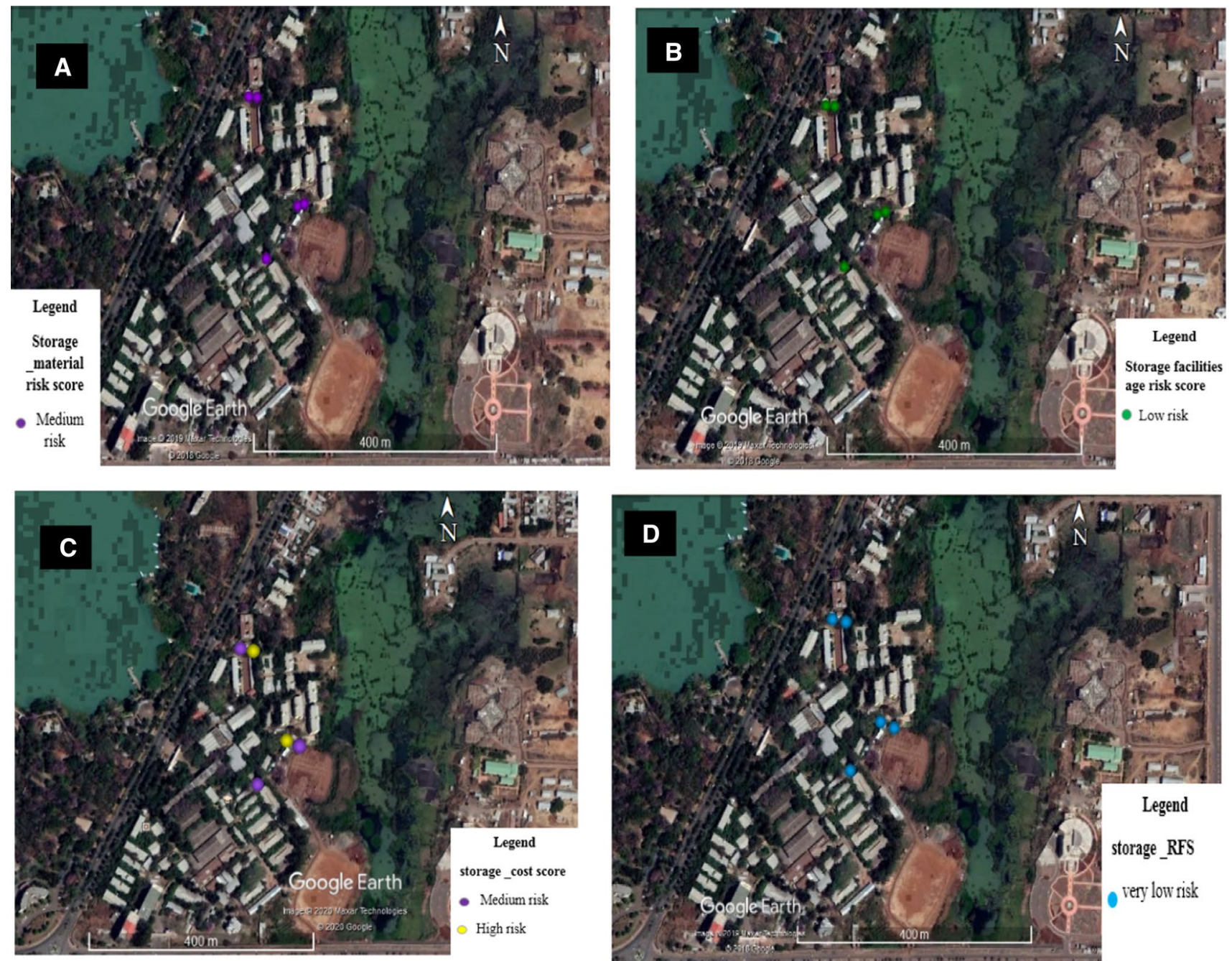

Fig. 9 Prioritization map of storage facilities risk of failure score(a-d)

\section{The risk associated with pipe}

Pipe diameter reported in $(\mathrm{mm})$ and grouped at different risk score values based on the corresponding size of the pipe. Shows in (Fig. 7a), BiT pipe diameter between (50-154 mm) ranges. The scores are laid under high risk and very high risk (Table 6). Considering all other variables constant, a water main with a larger diameter is expected to have higher thickness compared to a smaller diameter water main. The main reason for the higher frequency of failure is small diameter pipes have been attributed to reducing pipe strength wall thickness. The smaller pipes with thinner walls have a lower second moment of area, therefore, a reduced ability to resist loading and bending stress Kabir et al. (2015) and Rezaei, et.al (2015).

Many previous researchers indicated that the failure rates increase with the pipe age. However, age alone is a poor indicator of the necessity for replacement or rehabilitation.

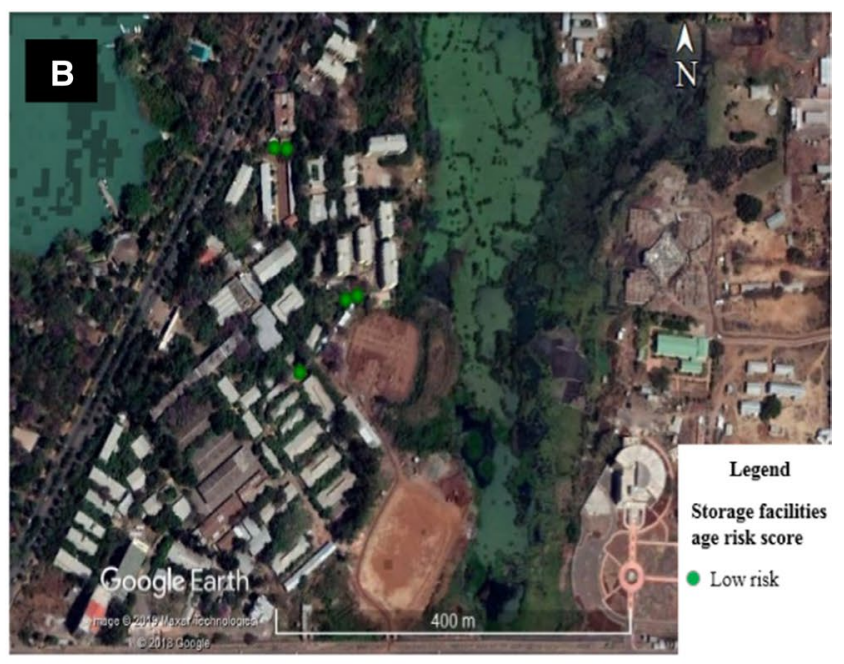

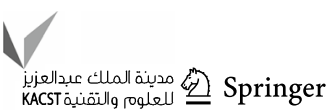



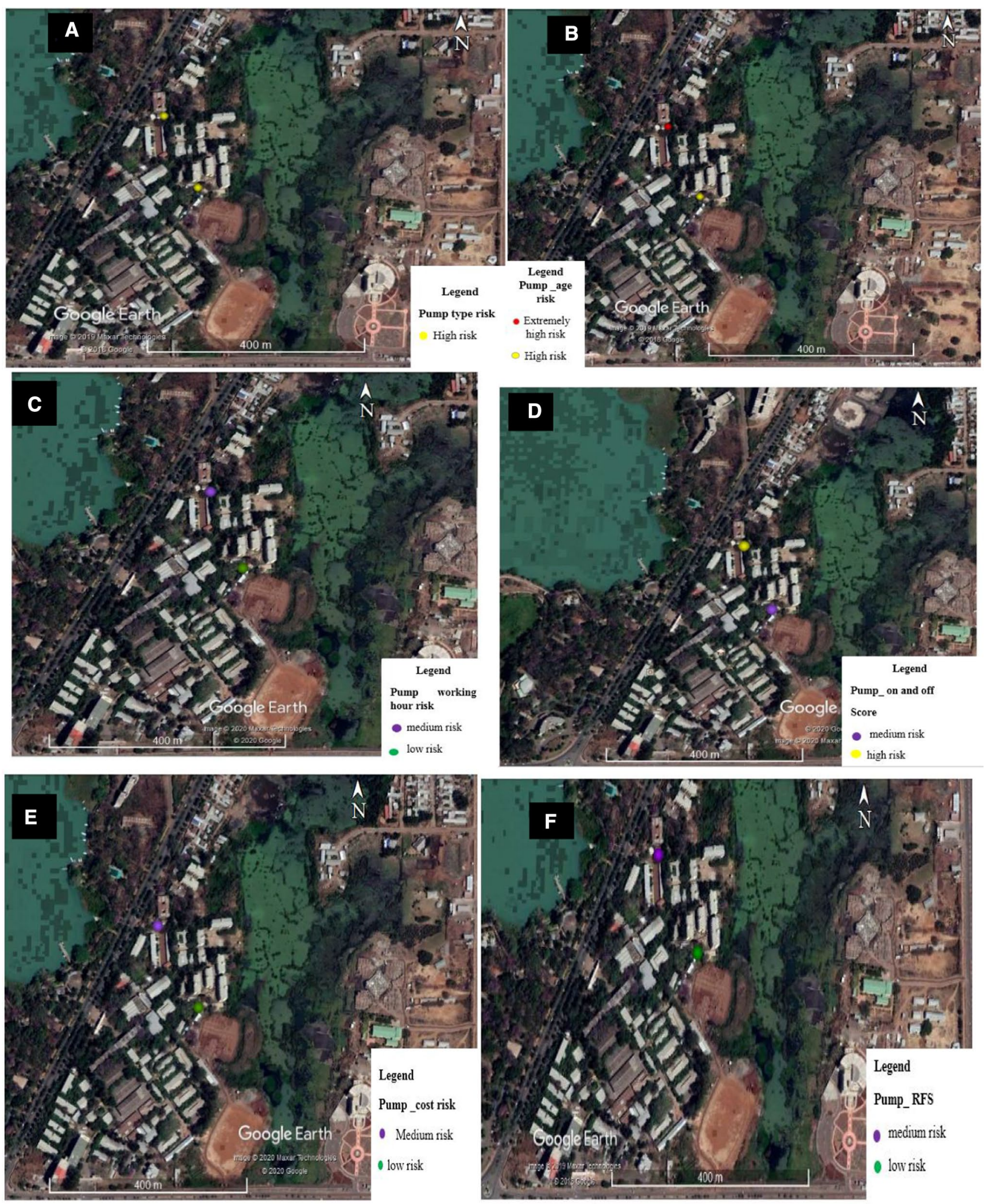

Fig. 10 Prioritize map of pump risk of failure score $(a-f)$ 
Rezaei et al. (2015) the study suggested that a strong positive correlation between pipe age and the number of pipe bursts. $\mathrm{Hu}$ and Hubble (2007) founds a general trend that the older the pipe age, the higher the pipe failure rate. Also, different installation year shows different failure characteristics J. Røstum (2000). (Figure 7b) shows a pipe age score of the study area based on pipe material type as J. Devera (2013) scored for the Arroyo Grande water distribution system. The age of the pipe shows that the BiT distribution system is under no risk level.

The study area water network pipe shows in the next (Fig. 7d), is dominated by GI pipe only a small portion of the pipe is covered by PVC. Based on the Anticipated service life (ASL) of pipe GI pipe it could susceptible to deterioration rather than PVC pipe (J. Devera 2013). Pipe length refers to the length of pipe between Nodes. As shown in the next (Fig. 7c), the probability of failure in the BiT water supply pipe is greater for the long pipe rather than the shorter one. The pipe failure and breaks are due to the length of the pipe because the more the length has the more affected by traffic load and operational stress.

However, the traffic load is less in the institution but some of the area, especially for those pipes which are laid in the direction of the gate of the institute was affected. For this case study, the variable of length score has been categorized according to Kabir et al. (2015) study. Loss and pipe break are straight proportional to pressure. High water pressure is a prominent cause of leaks, pipe damage, and water loss through the system Medhin (2017). The pressure at any point in the system should be maintained within a range where by the maximum pressure avoids pipe bursts and the minimum ensures that water is supplied at adequate flow rates for all expected demands (Fig. 7e). This may require pressure advancing or busting at strategic positions in the network. To determine the pressure score, the calibration analysis is performed for assuring the entered water distribution model input data accuracy before the decision-making process. The selection of sampling sites is typically based on situations of interest such as sampling taps placed close to mains American Water Works Association (1999).

In general, international proposed guidelines stipulate that for a medium to the highly detailed network model. The following limitations should be adopted (AWWA 1999) 3-6\% of nodes in the network should be tested for pressure readings. Three representative sample measurements to the water main spread throughout the study area have been selected for the calibration. Therefore, the computed pressure values were calibrated until the result was approached the observed pressure value. As per pressure criteria, $85 \%$ of the computed model results should become within $\pm 0.5 \mathrm{~m}$ head of the observed field conditions. Hence, to assure the acceptable level of calibration, the most commonly used model input parameter; pipe roughness was adjusted. As its mansion earlier the calibration work is done manually.

The model validation work was taken manually using the correlation coefficient equation $\left(\mathrm{R}_{2}\right)$ method and it was described as 0.839 . The assessed cost of the repair was defined as the cost to replace the material of the pipe only Cortez (2015). This study does not include excavation costs, cost of labor, or phasing because it was assumed that the price of the material would be reflective of including all other costs associate with a pipe replacement. The cost of the repair was also subjected to a scoring system, as mentioned before. As shown in (Fig. 7f) the majority of the pipe has under medium risk level based on the previously stated criteria.

As mentioned before Structural deterioration of water mains and their subsequent failure is affected by physical factors, external factors, and internal factors. The risk of failure score shows that from the total number of pipes $3.1 \%$ under medium risk of failure and the remaining pipe is which means $96.9 \%$ under low risk of failure. The cumulative effect of this factor Summarizes in (Fig. 8).
Fig. 11 Cumulative value of water quality index and corresponding score value
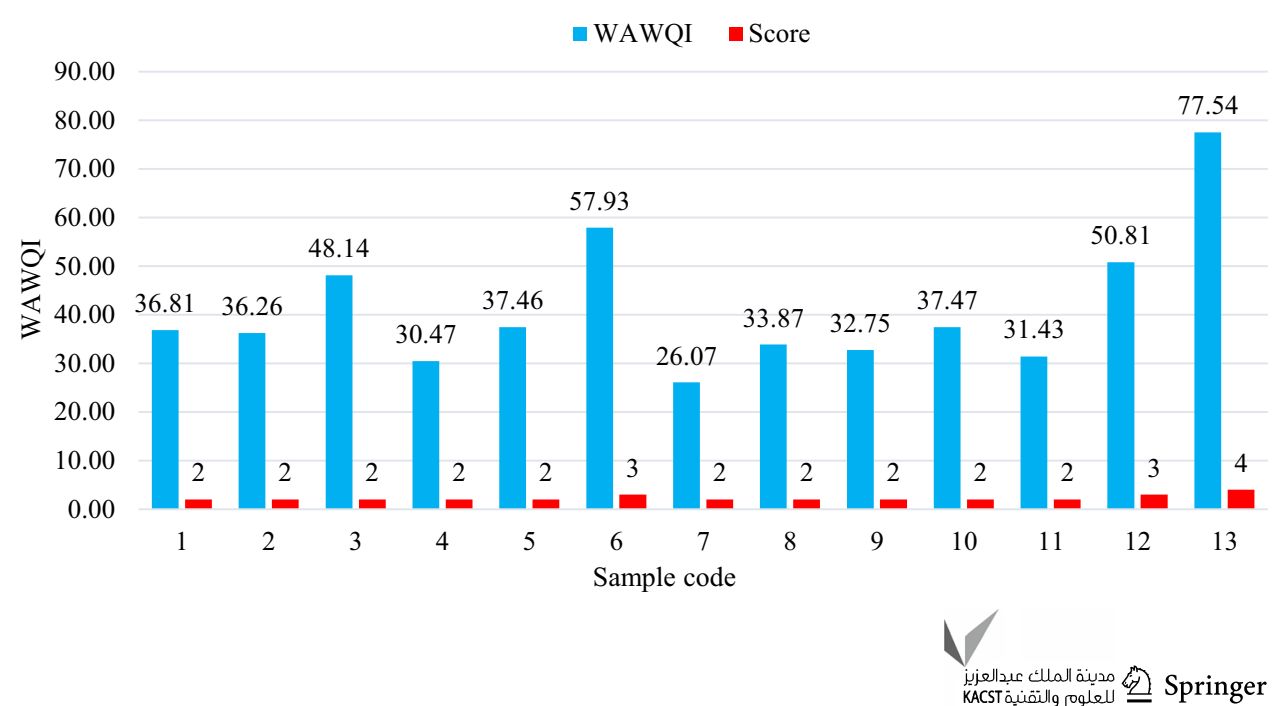


\section{The risk associated with storage facilities}

There are five water storage facilities in this study area. To evaluate the risk of failure for those water storage tanks and reservoirs, main and sub-main factors are selected according to the physical main factor score as explain in the previous step, based on the evaluation of the material score all storage facilities under a moderate risk of failure (Fig. 9a). According to the actual field data collected and calculated the remaining useful life of storage facilities, it is seen that the age score of the two reservoirs and the three tanks appears to have a low risk of failure based on age scores (Fig. 9b). Based on the information given from the Amhara waterworks construction bureau, the estimation of the final cost score of storage facilities can contain subjective and variable pricing parameters. Cost score evaluation of a replacement of storage facilities based on specific unit costs of raw materials used for construction. This can include total expenses for materials in terms of price per volume, and so on. It can also include the total costs for excavation, infill, pavement materials, and fittings. It does not contain prices associated with labor or any other services that have a variable or unspecified price. The cost score shows that the concrete reservoir was under a high-cost score than the other pioneer reservoir tanks (Fig. 9c). Finally, the commutative risk associated with storage facilities is very low (Fig. 9d).
Fig. 12 Measured flow rate of water at the tap

Fig. 13 Pressure head Vs flow rate of water at the tap
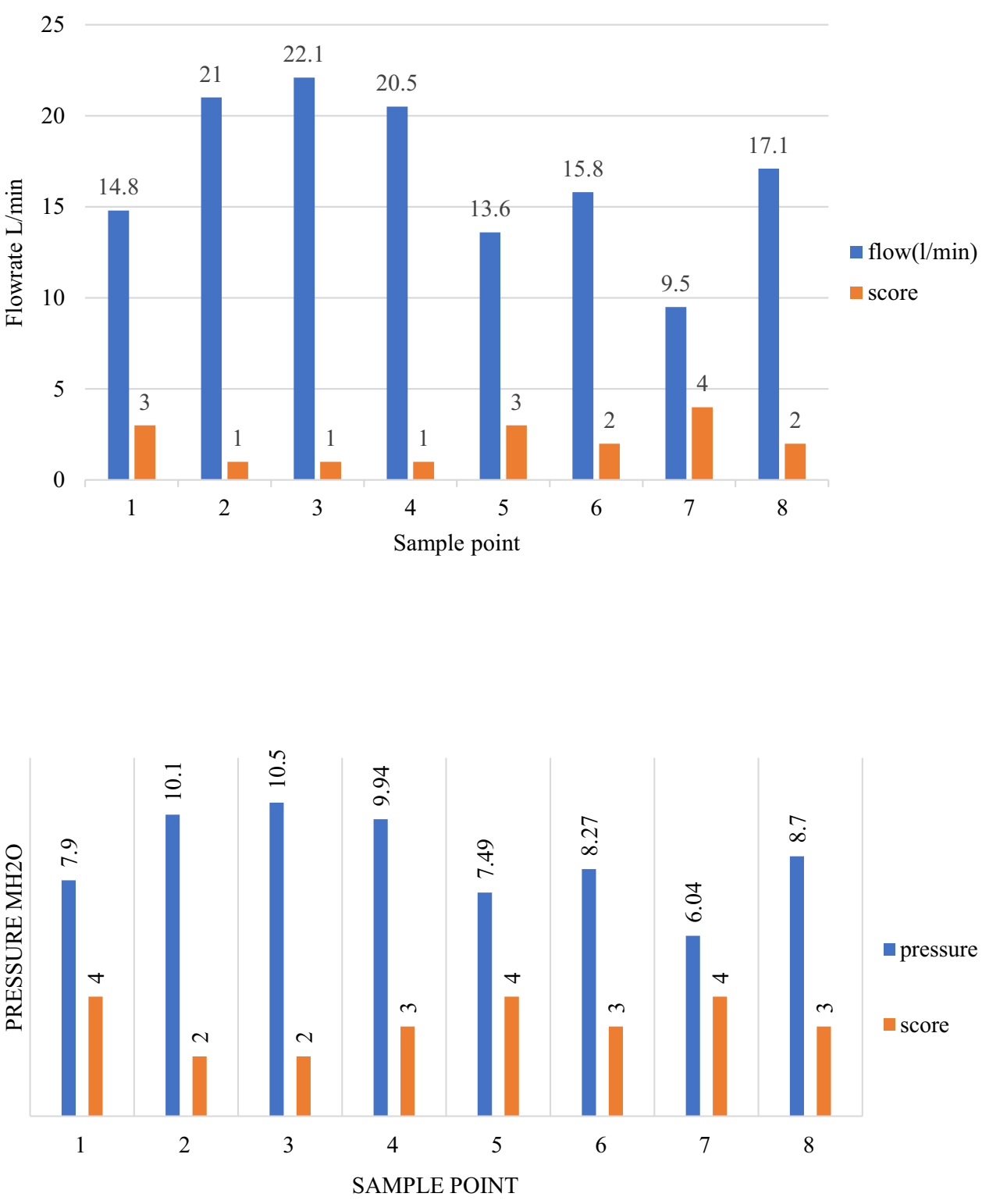


\section{The risk associated with pump}

In the case of BiT all pumps are a centrifugal type of pump, mentions earlier pump type score was laid on a high risk of failure score (Fig. 10a). For the subfactor of the physical main factor of the age of pump calculated result; the highest risk of failure score was obtained on the age of pump in the seven pumps currently it works at BiT distribution system. Among those seven pumps, three of those pumps are extremely high risk of failure the other one is at a high risk of failure (Fig. 10b). The operating time of the pump is exactly adjustable to satisfy the hydraulic requirement of the system. (Figure 10c) shows that the working hour of the pump risk score is under medium and low risk. according to a study, one of the major three problems attempt to improve pump operation of the existing pump station is inefficient pump scheduling. The frequency of off and on per day increase will increase the failure of the pump. As shown in (Fig. 10d), the BiT water pump is laid on a medium to high-risk score. according to the information given from the Amhara waterworks construction bureau, the cost of the pump is different from the other based on the type and manufacturing power of pumps. So, in this study according to the scores calculated for each pump, it was shown that the pump cost scores laid on medium and high-risk scores (Fig. 10e). After determining the data of different criteria of each water pump, the structural risk of failure of the score in appendix Table 5 shows that $42 \%$ of the total number of pumps under medium risk of failure score and $58 \%$ of the total number of pumps under low risk of failure score (Fig. 10f).

\section{Risk linked to customer}

The measured value of different water quality parameters of the collected water sample showed good water quality and a low risk to the user but in the same water quality parameters, there was a problem of unfit the seated national and international standards. In all sample places, there was a problem with chlorine dosage and coliform in both seasons. The use of chlorine is essential for ensuring that water is bacteriologically safe to drink. The cumulative average water quality index of BiT indicates that the water quality index level is 41.31 between (26-50) which is under good water quality and categorized under low risk (Fig 11).

Some of the reasons that were identified for deteriorating water quality in the distribution network are Crossconnections, leaking pipes, Lack of coverage, or venting of storage tanks, and Inadequate separation of supply lines from roadside ditches in the campus. The objective of this measurement was to observe how the flow rate of the piped water fit the required standards. The measured flow rate of water at the tap within the same time through the selected sample place shows that the minimum flow rate of water litter per minute is 9.5 at sample number 7 ( $\mathrm{C}$ and $\mathrm{D}$ male dormitory) and the maximum measured flow rate water is measured 22.1 litter per minute at sample number 3 (NDD classroom). Therefore, the average flow rate of water on tap for the BiT is $16.8 \mathrm{~L}$ per minute which is under very good range and a very low risk to the customer (Fig. 12).

Due to limited access to the pressure gauge difficult to measure the pressure at the same time through the selected sample place. To fix the problem, this relationship is an accurate way of measuring the pressure because, if pressure is measured more accurately way then, the pressure must be measured at the same time instead of individually. Then, the plotted graph shows that flow rate vs pressure head in $\mathrm{BiT}$ at the tap the flow rate increased pressure head increase (Fig. 13). The relationship equation between the pressure and the water flow rate according to (Fig. 13).

$y=(2.8195 x-7.5361)$

Therefore, by using the above equation it is possible to estimate the pressure concerning flow measured at the same time throughout the selected sample point. The pressure head in the case of BiT adequately shows on the lower range which indicates that there is a prominent gap in pressure adequacy and needs attention to increase the pressure head. According to the Ministry of Urban Development and Construction, (2013) building code standard, the water pressure in the main or other sources of supply residual water pressure should be at least $5 \mathrm{~m}$. Therefore, the average pressure is $8.61 \mathrm{mH} 20$. This pressure indicates that the BiT water pressure still in a Very good range meaning low to consumers.

\section{Water availability}

The problems associated with water shortage on Campus have increased in complexity over time. The Municipality of Bahir Dar was engaged at various levels to priorities water supply to BiT but this proved impossible to realize. The quantitative result also shows the water availability $<15 \mathrm{l} / \mathrm{c} /$ day it indicates low water availability and high risk to users.

\section{Estimation of risk index for BiT drinking water distribution system}

\section{Equal weight approach}

Equal weight ap is a type of weighting that gives the same weight or importance to each criterion and an equal weight index was calculated by giving each main and sub-main 
factor the same weight to achieve the proposed objectives. Thus, the risk index of the drinking water distribution system of Bahirdar institute of technology was (2.56) this value indicates that the institution drinking water distribution system risk index is laid under medium level with the sum up the effect of medium structural risk (CR) index (2.5) and medium consumption point (CPR) risk (2.62).

\section{Analytical hierarchy process (AHP) approach}

The questioner was prepared for the comparison among different criteria and sub-criteria.it was sent to experts and professionals from Bahir Dar city water Supply and sanitation service office, Amhara design and supervision work enterprise, and Amhara national regional state water, irrigation, and energy development bureau. The target group was only a person who is concerned with water supply distribution system installation and maintenance, consultant, and designer were selected as the purpose was to get prize comparison at each level of hierarchy among different variables. Their response includes pairwise comparisons among all variables of each category. (Fig.13) Twenty questionnaires were sent to different experts and consultants. Fifty present responses were received, which were incorporated to develop the global weight and priority of the deliberated factors.

Matrix of pairwise comparison for hieratical structure for developing risk index for Bahir Dar institute of technology drinking water supply distribution system will complete using the AHP excel template developed by Goepel (2013). The AHP output shows that structural risk has had the highest weight score $(76 \%)$ concerning consumption point risk (24\%). Also, the result of the drinking water distribution system risk index laid at the medium level (2.7), indicates the institution drinking water distribution system put at the acceptable condition. The AHP output gives priority for structural risk and henceforth, it is a sensitive parameter for risk assessment for drinking water system study. In addition to this, the change in structural risk weighting score result has a prominent effect on the result of the drinking water distribution system risk index associated with a consumption point risk.

In general, most answers to the questionnaires (made for experts) about BiT's drinking water distribution system structural risk and consumption point risk status indicate that the risk is moderate. Lastly, from the result of the structural risk index, the institute water supply system still needs improvement on the pipe diameter and age of the pump because the results show a high failure risk. Likewise, to structural risk, consumption point risk also needs improvement to water quality and water availability to achieve an excellent water distribution system.

\section{Conclusions}

From the result obtained and analysis made, the following conclusion has been arrived at: In this assessment, various criteria and sub-criteria were taken into account based on different literature reviews and the availability of data. This assessment was made into two main criteria which are customer point risk and structural point risks such as water quality, water availability, pressure head adequacy, the flow rate of water, pipe, storage facility, and pump. The risk of failure score which is taken from the literature was used in the technical evaluation of the distribution system component. The risk index of the drinking water distribution system was calculated by taking into account the structural risk failure scores and Consumption point risk score. To calculate the risk index Criteria, sub-criteria and alternatives were weighted by using the analytical hierarchical process, and equal-weighted approach. Based on the result obtained from an equal-weighted approach, the score of the drinking water distribution system risk index is at the medium level. Taken out from the expert's judgment or the results evaluated in the AHP method, structural risk has had the highest weight score, which means it needs more priority than consumption point risk. Finally, the investigated results indicate that the institute's drinking water distribution system risk put in satisfactory condition.

Author contribution Roman Abebe Mesalie, conceived the presented idea. We all Roman Abebe Mesalie, Mekash Shiferaw Kifelew, and Dagnachew Aklog developed the theory and performed the computations.

Funding The authors did not receive support from any organization for the submitted work.

\section{Declarations}

Conflicts of interest We (Authors) have to Declare that; we have no known personal relationships that could have appeared to influence the work reported in this paper.

Ethical statement The authors state that the research was conducted according to ethical standards and we declare that this manuscript is original, has not been published before, and is not currently being considered for publication elsewhere.

Ethics approval We confirm that the manuscript has been read and approved by all named authors. We further confirm and understand that the Corresponding Author is the sole contact for the Editorial process.

Consent for publication We the Author permitted the publication of the Work.

Consent to participate We the authors had voluntarily agree to participate in this research study. 
Open Access This article is licensed under a Creative Commons Attribution 4.0 International License, which permits use, sharing, adaptation, distribution and reproduction in any medium or format, as long as you give appropriate credit to the original author(s) and the source, provide a link to the Creative Commons licence, and indicate if changes were made. The images or other third party material in this article are included in the article's Creative Commons licence, unless indicated otherwise in a credit line to the material. If material is not included in the article's Creative Commons licence and your intended use is not permitted by statutory regulation or exceeds the permitted use, you will need to obtain permission directly from the copyright holder. To view a copy of this licence, visit http://creativecommons.org/licenses/by/4.0/.

\section{References}

Agrawal, C., \& Sinha, S. (2015). Infrastructure Asset Management: Risk Assessment: Al-barqawi, H., \& Zayed, T. (2006). Condition Rating Model for Underground Infrastructure

Al-Barqawi, H., Zayed, T. (2006). Condition rating model for underground infrastructure sustainable water mains. J Perform Constr Facil 20(2):126-135

American Water Works Association (1999). Calibration Guidelines for Water Distribution System Modelling. Engineering Computer Applications Committee, available online at http://www.awwa. org/unitdocs/592/calibrate.pdf.

Berardi, L., Giustolisi, O., Kapelan, Z., \& Savic, D. A. (2008). Development of pipe deterioration models for water distribution systems using EPR. Journal of Hydroinformatics.

Chandra, D. S., Asadi, S. S., \& Raju, M. V. S. (2014). Estimation of water quality index by weighted arithmetic water quality index method: a model study.

Dong Chen, Michael Saadeh, Steven Beck, K N (2013). Optimal Design of Water Distribution System to Minimize Risk of Water Main Breaks in Western Fort Wayne

Construction, M. of U. D. and. (2013). EBCS-9 Ethiopian Building Code Standard.

Cortez, H. (2015). A Risk Analysis Model for the Maintenance and Rehabilitation of Pipes in a Water Distribution System: A Statistical Approach. California Polytechnic State University.

Cubillo F, Pérez P (2014) Water Distribution System Risk Assessment Method. Proc Eng 89:355-362. https://doi.org/10.1016/j.proeng. 2014.11.199

Deepika BV, Ramakrishnaiah CR, Naganna SR (2020) Spatial variability of ground water quality: a case study of Udupi district, Karnataka State. India J Earth Syst Sci 129(1):1-20

Devera J C. (2013). Risk assessment model for pipe rehabilitation and replacement in a water distribution system. California Polytechnic State University

Ezell BC, Farr JV, Wiese I (2000) Infrastructure risk analysis model. J Infrastruct Syst 6(3):114-117

Goepel A K D. (2013). BPMSG AHP Excel Template with multiple Inputs, 1-6. Guyer, J. P. (2012). Introduction to Pumping Stations for Water Supply Systems, (877)

Howard G. (2003). Domestic Water Quantity, Service Level, and Health

Hu Y, Hubble, D W (2007). Factors contributing to the failure of asbestos cement water mains

Kabir G, Tesfamariam S, Francisque A, Sadiq, R. (2015). Evaluating the risk of water mains failure using a Bayesian belief network model.

A. J. Kettler and C. Goulter. (2010). An analysis of pipe breakage in urban water distribution networks.
Kilinç Y, Özdemir Ö, Orhan C, Firat M (2018) Evaluation of the technical performance of pipes in water distribution systems by analytic hierarchy process. Sustain Cities Soc 42:13-21. https://doi. org/10.1016/j.scs.2018.06.035

Kleiner Y, Rajani B (2001a) Comprehensive review of structural deterioration of water mains: statistical models. Urban Water 3(3):131-150

Kleiner Y, Rajani B (2001b) A comprehensive review of structural deterioration of water mains: a statistical model. Urban Water 3:131-150

Kumar A, Sharmab MP, Raic SP (2017) A novel approach for river health assessment of Chambal using fuzzy modelling. D W T 58:72-79

Kumar A, Taxak A.K, Mishra S, Pandey R. 2021. Long term trend analysis and suitability of water quality of River Ganga at Himalayan hills of Uttarakhand, India. Environmental Technology \& Innovation, 22, 101405

Lee L, Lu C, Kung SL (2004) Spatial diversity of chlorine residual in a drinking water distribution system. J Environ Eng 130(11):1263-1268

Lee SH (2012) Prioritizing water pipe replacement and rehabilitation by evaluating failure risk (Doctoral dissertation, Texas A \& M University)

Leonard M, Maier HR, Simpson AR, Zecchin AC, Roberts A, Berrisford MJ, Nixon JB (2004) Hydraulic risk assessment of water distribution systems. In: 8th National Conference on Hydraulics in Water Engineering

Li, H. (2007). Hierarchical Risk Assessment of Water Supply Systems, (March)

Lindhe A (2010) Risk Assessment and Decision Support for Managing Drinking Water Systems. Chalmers University of Technology Gothenburg, Sweden

Marzouk M, Hamid SA, M. E.-S. (2014) A methodology for prioritizing water mains rehabilitation in Egypt. Hous Build Nat Res Cent. https://doi.org/10.1016/j.hbrcj.2014.03.002

Mckee K. K, Forbes G, Mazhar, I, Entwistle R, Howard I. (2005). A review of major centrifugal pump failure modes with application to the water supply and sewerage industries, 1-12

Medhin s. (2017). Gis Based Decision Support System for Systematized Water Distribution Network Asset Management System: Case of Harar Town, Ethiopia, (January).

Mishra S, Kumar A, 2021. Estimation of physicochemical characteristics and associated metal contamination risk in the Narmada River, India. Environmental Engineering Research, 26(1)

Mudiyanselage R, Uditha S, Rathnayaka P. (2016). A Study of Water Pressure influence on Failure of Large

Pietrucha-Urbanik K (2015) Failure analysis and assessment on the exemplary water supply network. Eng Fail Analys 57:137-142. https://doi.org/10.1016/j.engfailanal.2015.07.036

Pietrucha-Urbanik K, Tchórzewska-Cieślak B (2017) Failure risk assessment in water network in terms of planning renewals - A case study of the exemplary water supply system. Water Pract Technol 12(2):274-286. https://doi.org/10.2166/wpt.2017.034

Rezaei H, Ryan B, Stoianov I (2015) Pipe failure analysis and impact of dynamic hydraulic conditions in water supply networks. Proc Eng 119:253-262. https://doi.org/10.1016/j.proeng.2015.08.883

Jon Røstum. (2000). Statistical Modelling of Pipe Failures in Water Supply Networks, (February), 106

Sadiq R, Rajani B. B, Kleiner Y. (2004). Risk analysis for water quality deterioration in distribution networks. National Research Council of Canada

Selvakumar J, Natarajan K. (2015). Failure analysis of centrifugal pumps based on survey

Sun J, Yu G (2013) Risk Assessment Modeling for Water Distribution Systems in Megacities 356:2957-2960 
The organization W. health. (2014). No Title. Ostfeld, A. (2015). Water distribution networks.

U.S. Department of energy energy efficiency and RenewableEnergy. (2006). Improving Pumping System Performance

WHO. (2011). Cleaning and disinfecting water storage tanks and tankers, $1-4$

WHO. (2018). A global overview of national regulations and standards for drinking-water quality

Yamijala S. (2007). a statistical estimation of water distribution system pipe break risk. Texas A\&M University
Yamijala S, Guikema SD, Brumbelow K (2008) Statistical models for the analysis of water distribution system pipe break data. Reliab Eng Syst Saf 94(2):282-293. https://doi.org/10.1016/j.ress.2008. 03.011

Zhou, Y. (2018). Deterioration and Optimal Rehabilitation Modelling for Urban Water Distribution Systems. Delft University of Technology, Netherlands. Retrieved from http://repository.tudel ft.nl/ihe 